
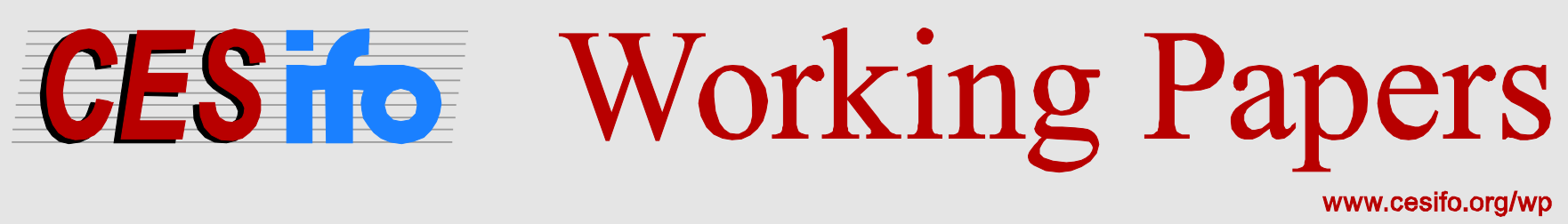

\title{
Animal Spirits and the International Transmission of Business Cycles
}

\author{
Paul De Grauwe \\ Yuemei Ji
}

\author{
CESIFO WORKING PAPER NO. 5810 \\ CATEgORY 7: MONETARy POLICY AND INTERNATIONAL FINANCE \\ MARCH 2016
}

Presented at CESifo Area Conference on Macro, Money \& International Finance, February 2016

An electronic version of the paper may be downloaded

- from the SSRN website:

- from the RePEc website:

- from the CESifo website:

www.SSRN.com

www.RePEc.org

www.CESifo-group.org/wp 


\title{
Animal Spirits and the International Transmission of Business Cycles
}

\begin{abstract}
It is well-known that the high synchronization of the business cycles among industrial countries cannot easily be replicated in standard open economy macroeconomic models without assuming that the exogenous shocks hitting these countries are highly correlated. We develop a twocountry behavioral macroeconomic model where the synchronization of the business cycle is produced endogenously. The main channel of synchronization occurs through a propagation of "animal spirits", i.e. waves of optimism and pessimism that become correlated internationally. We find that this propagation occurs with relatively low levels of trade integration. We also study the transmission of demand and supply shocks from one country to the other and find that the size of this transmission also depends on animal spirits. As a result, the size of the transmission depends on the timing of the shock.
\end{abstract}

JEL-Codes: E100.

Keywords: animal spirits, monetary policy, monetary union, business cycle.

Paul De Grauwe London School of Economics London / United Kingdom

P.C.De-Grauwe@lse.ac.uk
Juemei Ji

University College London

London / United Kingdom

Yuemei.Ji@ucl.ac.uk

The research in this paper was made possible by the European Commission's "Horizon 2020" research fund (Firstrun). It was presented at the CESifo area conference on Money, Macro and International Finance, 26-27 February 2016. 


\section{Introduction}

An important empirical feature of the international economy is the high correlation of the business cycles across countries. We show this feature both for the group of Eurozone countries and a group of industrialized countries outside the Eurozone. Table 1 presents the bilateral correlations of the business cycle component of the growth in GDP in the Eurozone. The business cycle component is obtained by using a Hodrick-Prescott (HP) filter on the data of GDP growth. We apply a similar procedure for the group on industrial countries outside the Eurozone.

It is striking to find how high these correlation coefficients are. This is especially the case within the Eurozone were we find many correlation coefficients of the business cycle components exceeding 0.9. On average we find that this correlation coefficient is 0.82 , suggesting a very high degree of synchronization of the business cycles within the Eurozone. This is confirmed in Figure 1 showing the evolution of the business cycle components of GDP growth in the Eurozone. This clearly shows that Eurozone countries have experienced more or less the same business cycle movements since 1995. If there is a difference between these countries it is to be found in the amplitude of the business cycle movements (see De Grauwe and Ji(2016)) for an analysis of the implications of these different amplitudes). We are aware of the fact that the measures of business cycle synchronization may result in different results. However, our findings are consistent with the existing findings. For a survey of this literature, see de Haan et al. (2008).

Outside the Eurozone we observe smaller bilateral correlations of the business cycles than in the Eurozone. However, these correlations can still be called quite high. They often reach levels of 0.6 or more. Poland stands out as the only country with negative correlations. The average of all the correlation coefficients in table 2 is 0.61 . Thus it appears that in the group of industrial countries outside the Eurozone business cycles are also quite synchronized.

There exists empirical evidence that the degree of synchronization of the business cycles is influenced by the degree of trade integration. Frankel and 
Rose(1998) found that increasing trade integration leads to more synchronization of the business cycles. This has been confirmed by other empirical studies (see Artis and Cleays(2005), Bordo and Helbling(2004)).

Table 1: Bilateral correlations of the business cycle component of GDP growth in Eurozone countries(1995-2014)

\begin{tabular}{|c|c|c|c|c|c|c|c|c|c|c|c|}
\hline & Austria & Belgium & Finland & France & Germany & Greece & Ireland & Italy & Netherl & Portugal & Spain \\
\hline Austria & 1,00 & & & & & & & & & & \\
\hline Belgium & 0,97 & 1,00 & & & & & & & & & \\
\hline Finland & 0,97 & 0,98 & 1,00 & & & & & & & & \\
\hline France & 0,93 & 0,95 & 0,97 & 1,00 & & & & & & & \\
\hline Germany & 0,69 & 0,57 & 0,55 & 0,59 & 1,00 & & & & & & \\
\hline Greece & 0,73 & 0,82 & 0,84 & 0,74 & 0,09 & 1,00 & & & & & \\
\hline Ireland & 0,85 & 0,89 & 0,92 & 0,95 & 0,41 & 0,81 & 1,00 & & & & \\
\hline Italy & 0,91 & 0,96 & 0,98 & 0,96 & 0,50 & 0,86 & 0,93 & 1,00 & & & \\
\hline Netherlands & 0,93 & 0,94 & 0,93 & 0,91 & 0,60 & 0,75 & 0,86 & 0,90 & 1,00 & & \\
\hline Portugal & 0,98 & 0,89 & 0,89 & 0,87 & 0,37 & 0,82 & 0,87 & 0,90 & 0,94 & 1,00 & \\
\hline Spain & 0,85 & 0,91 & 0,94 & 0,87 & 0,27 & 0,97 & 0,90 & 0,95 & 0,86 & 0,90 & 1,00 \\
\hline
\end{tabular}

\section{Source: OECD}

Table2: Bilateral correlations of the business cycle component of GDP growth in non-Eurozone countries(1995-2014)

\begin{tabular}{|c|c|c|c|c|c|c|c|c|c|c|c|c|c|}
\hline & Australia & Canada & Czech & Denmark & Hungary & Japan & Korea & Norway & Poland & Sweden & Switzerland & UK & US \\
\hline Australia & 1,00 & & & & & & & & & & & & \\
\hline Canada & 0,81 & 1,00 & & & & & & & & & & & \\
\hline Czech & 0,41 & 0,24 & 1,00 & & & & & & & & & & \\
\hline Denmark & 0,84 & 0,90 & 0,61 & 1,00 & & & & & & & & & \\
\hline Hungary & 0,83 & 0,79 & 0,67 & 0,88 & 1,00 & & & & & & & & \\
\hline Japan & 0,48 & 0,60 & 0,63 & 0,71 & 0,69 & 1,00 & & & & & & & \\
\hline Korea & 0,63 & 0,75 & 0,48 & 0,76 & 0,81 & 0,54 & 1,00 & & & & & & \\
\hline Norway & 0,85 & 0,87 & 0,56 & 0,95 & 0,87 & 0,66 & 0,69 & 1,00 & & & & & \\
\hline Poland & 0,07 & $-0,09$ & 0,50 & 0,20 & $-0,04$ & 0,01 & $-0,06$ & 0,14 & 1,00 & & & & \\
\hline Sweden & 0,80 & 0,87 & 0,62 & 0,96 & 0,86 & 0,80 & 0,78 & 0,87 & 0,21 & 1,00 & & & \\
\hline Switzerland & 0,22 & 0,29 & 0,67 & 0,57 & 0,29 & 0,47 & 0,27 & 0,51 & 0,75 & 0,55 & 1,00 & & \\
\hline UK & 0,88 & 0,91 & 0,52 & 0,93 & 0,95 & 0,73 & 0,80 & 0,92 & $-0,10$ & 0,90 & 0,30 & 1,00 & \\
\hline US & 0,87 & 0,96 & 0,33 & 0,93 & 0,83 & 0,64 & 0,67 & 0,92 & $-0,04$ & 0,88 & 0,30 & 0,93 & 1,00 \\
\hline
\end{tabular}

Trade integration is one explanatory factor, but it does not explain everything. This is made clear by figures 2 and 3 which plots the bilateral correlation coefficients obtained from tables 1 and 2 with the bilateral trade flows (as a percent of the sum of the GDPs of the pairs of countries involved). We observe that there is a positive relation between the degree of bilateral trade integration 
and bilateral correlations. This relation, however, is weak and explains only a small fraction of the variation in the bilateral correlations. Clearly there are other mechanisms at work driving the synchronization of business cycles. It is the intention of this paper to uncover these other mechanisms.

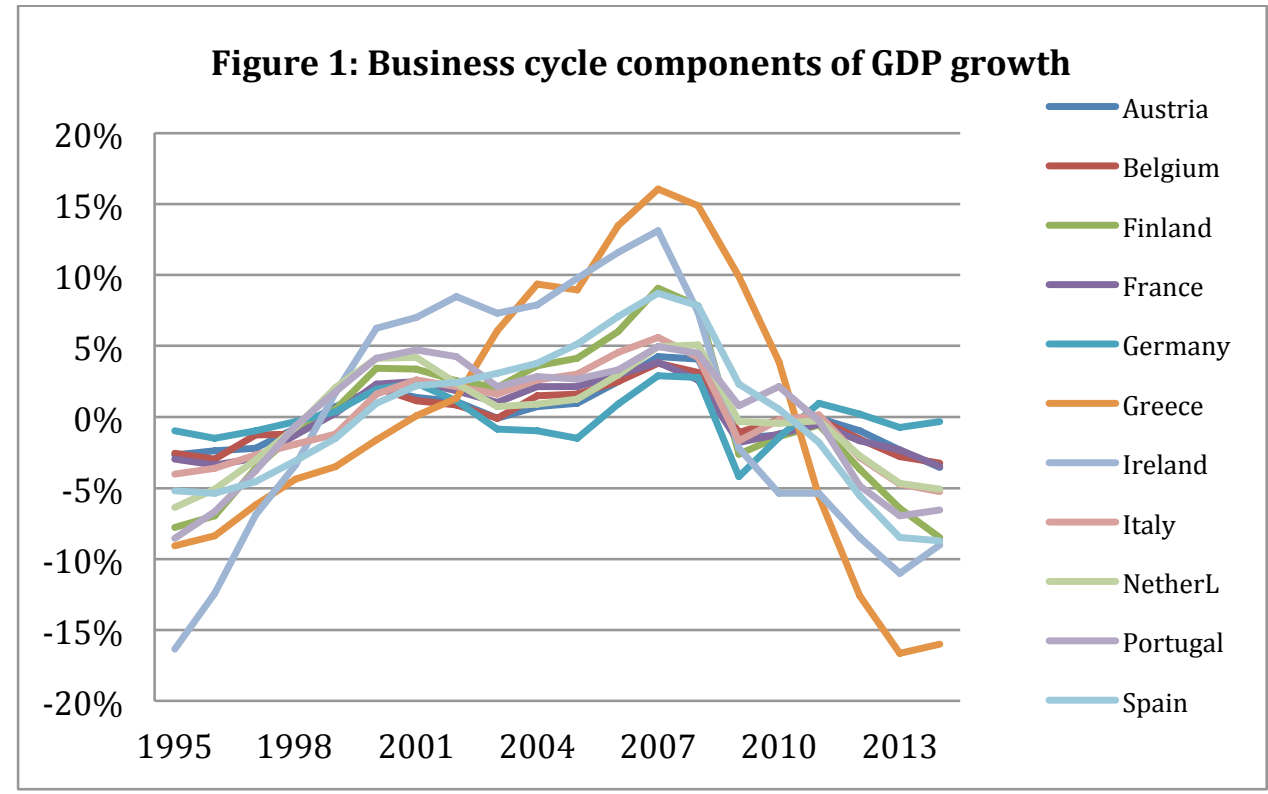

Source: De Grauwe and Ji(2016)

Figure 2: Correlation of business cycle and trade links in 11 Eurozone countries

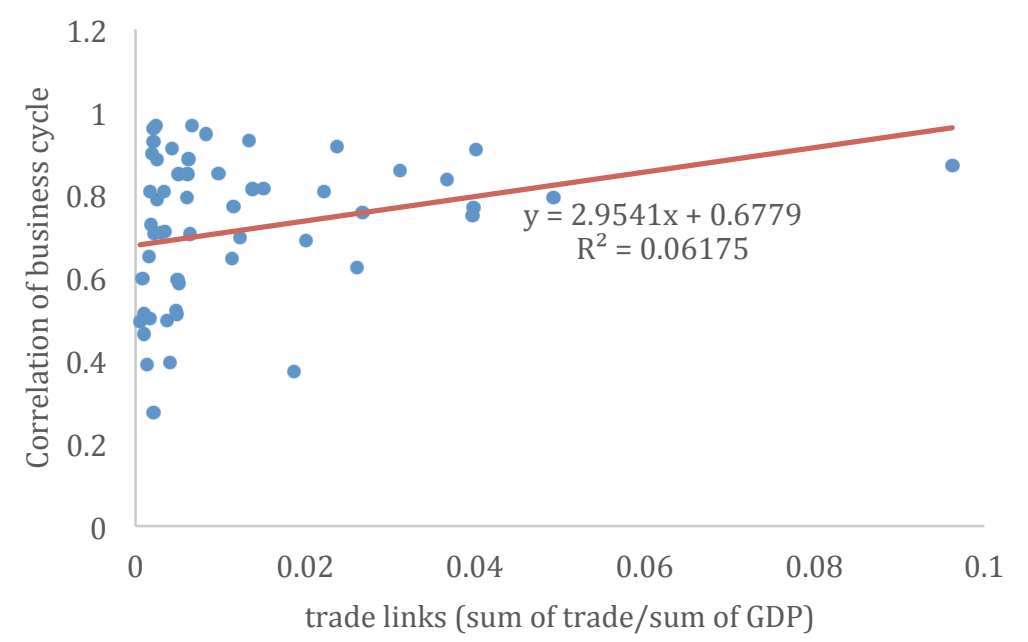




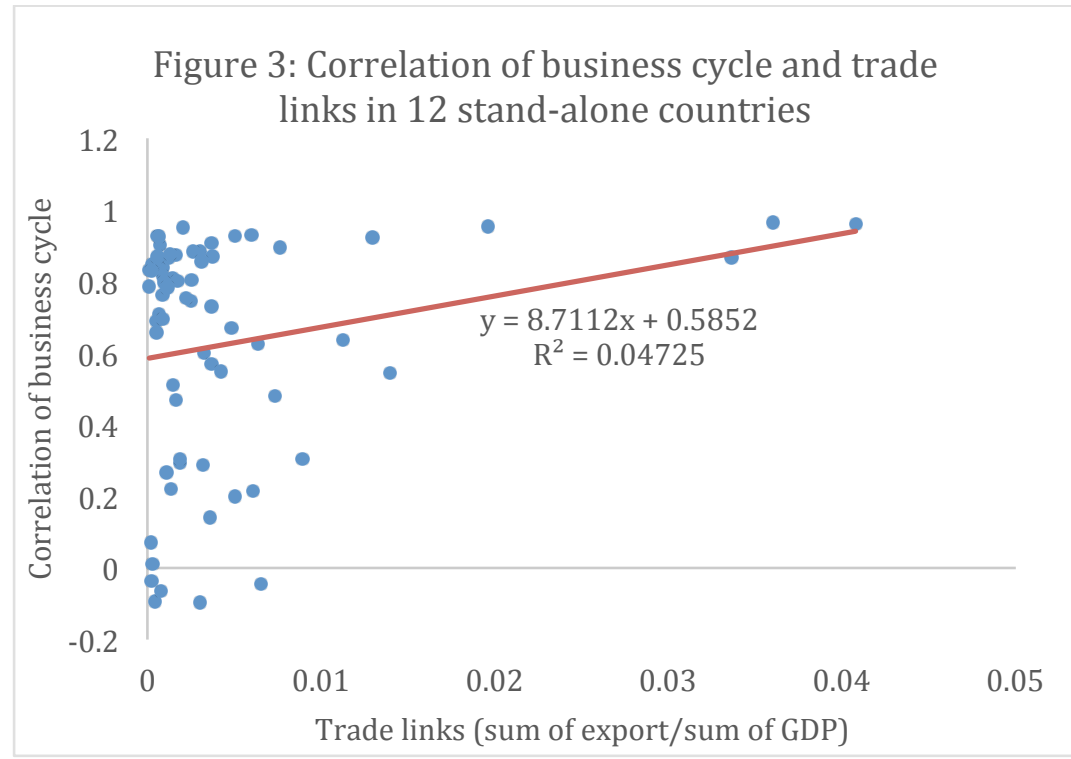

Source: authors' own estimation using data from OECD and IMF, direction of trade

Mainstream macroeconomic models (both real business cycle models and DSGE models) have found it difficult to replicate the observed high synchronization of business cycles in the industrialized world. This problem was first pointed out by Backus et al.(1992) who found that standard open economy versions of real business cycle models could not explain the high level of synchronization of the business cycles across countries (see also Canova and Dellas(1993)). Open economy versions of DSGE-models have experienced the same problem (see Alpanda and Aysun(2014)). Of course one can solve these problems in these models by assuming high positive correlations of exogenous shocks. But this is not really an explanation as it forces the designers of these models to admit that high correlations of the business cycles across countries are produced outside their models. This is not a very satisfactory analysis.

There have been attempts to explain the high synchronization of the business cycles across countries by introducing financial integration in the models (see e.g. Gertler et al.(2007), Devereux and Yetman(2010), Alpanda and Aysun(2014)). This goes some way in explaining this synchronization. But again too much is "explained" by introducing highly correlated exogenous financial shocks. 
In this paper we want to go further. First we want to analyze the mechanism through which business cycles are synchronized across countries that trade with each other. We will do this using a behavioral macroeconomic model similar to De Grauwe (2012) but in a two-county setting. We will show that the transmission of business cycle movements is made possible by a dynamics that leads to correlation of "animal spirits" across countries. Second, using the same behavioral model we will analyze how a shock (e.g. a demand shock produced by a fiscal expansion) that originates in one country is transmitted to the other country.

The rest of the paper is organized as follows. Section 2 presents a two-country version of our behavioral macroeconomic model. Section 3 uses this model to analyze the factors that affect the synchronization of the business cycles and section 4 focuses on the transmission of a demand shock in country 1 to country 2.

\section{The two-country behavioral model}

\subsection{Basic model}

Following De Grauwe (2012), we use a simple behavioural macroeconomic model and we extend it to two countries that trade with each other. The basic structure of this behavioural model is the same as the mainstream NewKeynesian model as described in e.g. Gali(2008). The model consists of two aggregate demand equations, two aggregate supply equations and a Taylor rule. To keep the model simple, we assume that the two countries are symmetric and therefore exhibit the same parameters. We will also discuss the model in two monetary regimes, one is in a monetary union with a common central bank and a common short-term interest rate, the other regime is two countries with their own independent central banks and different interest rates. In the second regime, we will have two independent Taylor rules.

The aggregate demand equations for countries 1 and 2 are specified in the standard way, i.e. 


$$
\begin{aligned}
& y_{t}^{1}=a_{1} \tilde{E}_{t} y_{t+1}^{1}+\left(1-a_{1}\right) y_{t-1}^{1}+a_{2}\left(r_{t}-\tilde{E}_{t} \pi_{t+1}^{1}\right)+\left(x_{t}^{1}-m_{t}^{1}\right)+\varepsilon_{t}^{1} \\
& y_{t}^{2}=a_{1} \tilde{E}_{t} y_{t+1}^{2}+\left(1-a_{1}\right) y_{t-1}^{2}+a_{2}\left(r_{t}-\tilde{E}_{t} \pi_{t+1}^{2}\right)+\left(x_{t}^{2}-m_{t}^{2}\right)+\varepsilon_{t}^{2}
\end{aligned}
$$

where $y_{t}^{1}$ and $y_{t}^{2}$ are the output gaps for country 1 and 2 in period $t, r_{t}$ is the nominal interest rate, $\pi_{t}^{1}$ and $\pi_{t}^{2}$ are the rates of inflation for country 1 and 2 in period t, and $\varepsilon_{t}^{1}$ and $\varepsilon_{t}^{2}$ are white noise disturbance terms for country 1 and $2 . \widetilde{E}_{t}^{i}$ is the expectations operator where the tilde above $E$ refers to expectations that are not formed rationally. This process will be specified subsequently. We follow the procedure introduced in New Keynesian macroeconomic models of adding a lagged output $y_{t-1}^{1}$ and $y_{t-1}^{2}$ in the demand equation (see Gali(2008) and Woodford(2003)). This is usually justified by invoking habit formation. We also take into account trade link between the two countries: $x_{t}^{1}$ and $x_{t}^{2}$ as the exports of countries 1 and 2, $m_{t}^{1}$ and $m_{t}^{2}$ the imports of countries 1 and 2. These variables are also defined as gaps, i.e. the difference between the actual values and the values obtained in the steady state when the output gap is zero. Assuming that the import propensity, $m$, is the same in both countries and that the two countries only trade with each other, the aggregate demand equations for countries 1 and 2 can be rewritten as follows:

$$
\begin{aligned}
& y_{t}^{1}=\frac{a_{1}}{1+m} \widetilde{E}_{t} y_{t+1}^{1}+\frac{1-a_{1}}{1+m} y_{t-1}^{1}+\frac{a_{2}}{1+m}\left(r_{t}-\widetilde{E}_{t} \pi_{t+1}^{1}\right)+\frac{m}{1+m} y_{t}^{2}+\varepsilon_{t}^{1} \\
& y_{t}^{2}=\frac{a_{1}}{1+m} \widetilde{E}_{t} y_{t+1}^{2}+\frac{1-a_{1}}{1+m} y_{t-1}^{2}+\frac{a_{2}}{1+m}\left(r_{t}-\widetilde{E}_{t} \pi_{t+1}^{2}\right)+\frac{m}{1+m} y_{t}^{1}+\varepsilon_{t}^{2}
\end{aligned}
$$

The aggregate demand equation has a very simple interpretation. Utility maximizing agents will want to spend more on goods and services today when they expect future income (output gap) to increase and to spend less when the real interest rate increases. Moreover, the existence of trade between the two countries creates a positive link between the output gaps of these countries.

The aggregate supply equation is derived from profit maximization of individual producers (see Gali(2008), chapter 3). In addition, it is assumed that producers 
cannot adjust their prices instantaneously. Instead, for institutional reasons, they have to wait to adjust their prices. The most popular specification of this price adjustment mechanism is the Calvo pricing mechanism (Calvo(1983)). This assumes that in period $t$, a fraction of prices remains unchanged. Under those conditions the aggregate supply equation for countries 1 and 2 (which is often referred to as the New Keynesian Philips curve) can be derived as :

$$
\begin{aligned}
& \pi_{t}^{1}=b_{1} \widetilde{E}_{t} \pi_{t+1}^{1}+\left(1-b_{1}\right) \pi_{t-1}^{1}+b_{2} y_{t}^{1}+\eta_{t}^{1} \\
& \pi_{t}^{2}=b_{1} \widetilde{E}_{t} \pi_{t+1}^{2}+\left(1-b_{1}\right) \pi_{t-1}^{2}+b_{2} y_{t}^{2}+\eta_{t}^{2}
\end{aligned}
$$

Equations (3)-(6) determine the four endogenous variables, inflation $\pi_{t}^{1}$ and $\pi_{t}^{2}$, and output gap $\mathrm{y}_{t}^{1}$ and $\mathrm{y}_{t}^{2}$, given the nominal interest rate $r_{t}$. The model has to be closed by specifying the way the nominal interest rate is determined. The most popular way to do this has been to invoked the Taylor rule (see Taylor(1993)) that describes the behavior of the central bank. In a monetary union, this rule is written as follows:

$$
r_{t}=c_{1}\left(\overline{\pi_{t}}-\pi^{*}\right)+c_{2} \overline{y_{t}}+c_{3} r_{t-1}+u_{t}
$$

where $\overline{\pi_{t}}=\frac{1}{2}\left(\pi_{t}^{1}+\pi_{t}^{2}\right)$ and $\overline{y_{t}}=\frac{1}{2}\left(y_{t}^{1}+y_{t}^{2}\right), \pi^{*}$ is the inflation target. Thus the central bank is assumed to raise the interest when the observed inflation rate increases relative to the announced inflation target. The intensity with which it does this is measured by the coefficient $c_{1}$. It has been shown (see Woodford(2003), chapter 4, or Gali(2008)) that it must exceed 1 for the model to be stable. This is also sometimes called the "Taylor principle"1.

When the output gap increases the central bank is assumed to raise the interest rate. The intensity with which it does this is measured by $c_{2}$. The latter parameter then also tells us something about the ambitions the central bank has to stabilize output. A central bank that does not care about output stabilization sets $c_{2}=0$. We say that this central bank applies strict inflation targeting. Finally,

\footnotetext{
${ }^{1}$ Ideally, the Taylor rule should be formulated using a forward-looking inflation variable, i.e. central banks set the interest rate on the basis of their forecasts about the rate of inflation. This is not done here in order to maintain simplicity in the model (again see Woodford(2003), p. 257). As is shown in Woodford(2003) forward looking Taylor rules may not lead to a determinate solution even if the Taylor principle is satisfied.
} 
note that, as is commonly done, the central bank is assumed to smooth the interest rate. This smoothing behavior is represented by the lagged interest rate in equation (7).

We have added error terms in each of the equations. These error terms describe the nature of the different shocks that can hit the economy. There are demand shocks $\varepsilon_{t}^{1}$ and $\varepsilon_{t}^{2}$, supply shocks $\eta_{t}^{1}$ and $\eta_{t}^{2}$, and interest rate shocks, $u_{t}$. We will generally assume that these shocks are normally distributed with mean zero and a constant standard deviation. We will allow these shocks to be correlated across countries.

As mentioned earlier, we will also want to apply this model in a regime in which the two countries are not member of a monetary union, i.e. they have their own independent central banks and two short term interest rates. Accordingly, the aggregate demand equations can then be rewritten as:

$$
\begin{aligned}
& y_{t}^{1}=\frac{a_{1}}{1+m} \tilde{E}_{t} y_{t+1}^{1}+\frac{1-a_{1}}{1+m} y_{t-1}^{1}+\frac{a_{2}}{1+m}\left(r_{t}^{1}-\tilde{E}_{t} \pi_{t+1}^{1}\right)+\frac{m}{1+m} y_{t}^{2}+\varepsilon_{t}^{1} \\
& y_{t}^{2}=\frac{a_{1}}{1+m} \tilde{E}_{t} y_{t+1}^{2}+\frac{1-a_{1}}{1+m} y_{t-1}^{2}+\frac{a_{2}}{1+m}\left(r_{t}^{2}-\tilde{E}_{t} \pi_{t+1}^{2}\right)+\frac{m}{1+m} y_{t}^{1}+\varepsilon_{t}^{2}
\end{aligned}
$$

The Taylor rule in each central bank can be written as follows:

$$
\begin{aligned}
& r_{t}^{1}=c_{1}\left(\pi_{t}^{1}-\pi^{*}\right)+c_{2} y_{t}^{1}+c_{3} r_{t-1}^{1}+u_{t}^{1} \\
& r_{t}^{2}=c_{1}\left(\pi_{t}^{2}-\pi^{*}\right)+c_{2} y_{t}^{2}+c_{3} r_{t-1}^{2}+u_{t}^{2}
\end{aligned}
$$

Clearly in this version of the model there is an exchange rate that will vary as central banks set their interest rates independently. We will disregard this exchange rate channel here and leave this for further research.

\subsection{Introducing heuristics in forecasting output and inflation}

In the world of rational expectations that forms the basis of the mainstream model agents are assumed to understand the complexities of the world. In contrast, we take the view that agents have cognitive limitations. They only understand tiny little bits of the world. In such a world agents are likely to use simple rules, heuristics, to forecast the future (see e.g. Damasio 2003; Kahneman 2002; Camerer et al. 2005). 
Agents who use simple rules of behavior are no fools. They use simple rules only because the real world is too complex to understand, but they are willing to learn from their mistakes, i.e. they regularly subject the rules they use to some criterion of success. This leads to the concept of adaptive learning.

Adaptive learning is a procedure whereby agents use simple forecasting rules and then subject these rules to a "fitness" test, i.e., agents endogenously select the forecasting rules that have delivered the highest performance ("fitness") in the past. Thus, an agent will start using one particular rule. She will regularly evaluate this rule against the alternative rules. If the former rule performs well, she keeps it. If not, she switches to another rule. In this sense the rule can be called a "trial and error" rule.

This "trial and error" selection mechanism acts as a disciplining device on the kind of rules that are acceptable. Not every rule is acceptable. It has to perform well. What that means will be made clear later. It is important to have such a disciplining device, otherwise everything becomes possible. The need to discipline the forecasting rule was also one of the basic justifications underlying rational expectations. By imposing the condition that forecasts must be consistent with the underlying model, the model builder severely limits the rule that agents can use to make forecasts. The adaptive selections mechanism used here plays a similar disciplining role.

Agents are assumed to use simple rules (heuristics) to forecast the future output and inflation. The way we proceed is as follows. we assume two types of forecasting rules. A first rule can be called a "fundamentalist" one. Agents estimate the steady state value of the output gap (which is normalized at 0 ) and use this to forecast the future output gap. In De Grauwe(2012) this rule is extended to the case in which agents do not know the steady state output gap with certainty and only have biased estimates of it). A second forecasting rule is an "extrapolative" one. This is a rule that does not presuppose that agents know the steady state output gap. They are agnostic about it. Instead, they extrapolate the previous observed output gap into the future.

The two rules that are followed in the two countries are specified as follows: 
The fundamentalist rule is defined by $\widetilde{E}_{t}^{f} y_{t+1}=0$

The extrapolative rule is defined by $\widetilde{E}_{t}^{e} y_{t+1}=y_{t-1}$

We have dropped the country superscripts here (and in what follows). Thus equations (12) and (13) apply to agents in both countries.

This kind of simple heuristic has often been used in the behavioral finance literature where agents are assumed to use fundamentalist and chartist rules (see Brock and Hommes(1997), Branch and Evans(2006), De Grauwe and Grimaldi(2006)). The rules are simple in the sense that they only require agents to use information they understand, and do not require them to understand the whole picture. Some experimental evidence in support of the two rules similar to (12) and (13) for inflation forecasts in a New Keynesian model can be found in a paper by Pfajfar and Zakelj (2009).

The market forecast is obtained as a weighted average of these two forecasts, i.e.

$$
\begin{aligned}
& \widetilde{E}_{t} y_{t+1}=\alpha_{f, t} \widetilde{E}_{t}^{f} y_{t+1}+\alpha_{c, t} \widetilde{E}_{t}^{e} \\
& \widetilde{E}_{t} y_{t+1}=\alpha_{f, t} 0+\alpha_{c, t} y_{t-1}
\end{aligned}
$$

where $\alpha_{f, t}$ and $\alpha_{e, t}$ are the probabilities that agents use a fundamentalist, respectively, an extrapolative rule and $\alpha_{f, t}+\alpha_{e, t}=1$.

\section{Selecting the forecasting rules}

As indicated earlier, agents in our model are willing to learn, i.e. they continuously evaluate their forecast performance. This willingness to learn and to change one's behavior is the most fundamental definition of rational behavior. Our agents are rational in the sense that they learn from their mistakes. The concept of "bounded rationality" is often used to characterize this behavior.

The first step in the analysis then consists in defining a criterion of success. This will be the forecast performance of a particular rule. Thus in this first step, agents compute the forecast performance of the two different forecasting rules as follows:

$$
U_{f, t}=-\sum_{k=0}^{\infty} \omega_{k}\left[y_{t-k-1}-\tilde{E}_{f, t-k-2} y_{t-k-1}\right]^{2}
$$




$$
U_{e, t}=-\sum_{k=0}^{\infty} \omega_{k}\left[y_{t-k-1}-\tilde{E}_{e, t-k-2} y_{t-k-1}\right]^{2}
$$

where $U_{f, t}$ and $U_{e, t}$ are the forecast performances (utilities) of the fundamentalist and extrapolating rules, respectively. These are defined as the mean squared forecasting errors (MSFEs) of the forecasting rules; $\omega_{k}$ are geometrically declining weights. We make these weights declining because we assume that agents tend to forget. Put differently, they give a lower weight to errors made far in the past as compared to errors made recently.

The next step consists in evaluating these forecast performances (utilities). We apply discrete choice theory (see Anderson, de Palma, and Thisse, (1992) for a thorough analysis of discrete choice theory and Brock \& Hommes(1997) for the first application in finance) in specifying the procedure agents follow in this evaluation process. If agents were purely rational they would just compare $U_{f, t}$ and $U_{e, t}$ in (16) and (17) and choose the rule that produces the highest value. Thus under pure rationality, agents would choose the fundamentalist rule if $U_{f, t}>$ $U_{e, t}$, and vice versa. However, things are not so simple. Psychologists have found out that when we have to choose among alternatives we are also influenced by our state of mind. The latter is to a large extent unpredictable. It can be influenced by many things, the weather, recent emotional experiences, etc. One way to formalize this is that the utilities of the two alternatives have a deterministic component (these are $U_{f, t}$ and $U_{e, t}$ in (16) and (17)) and a random component $\varepsilon_{f, t}$ and $\varepsilon_{e, t}$ The probability of choosing the fundamentalist rule is then given by

$$
\alpha_{f, t}=P\left[\left(U_{f, t}+\varepsilon_{f, t}\right)>\left(U_{e, t}+\varepsilon_{e, t}\right)\right]
$$

In words, this means that the probability of selecting the fundamentalist rule is equal to the probability that the stochastic utility associated with using the fundamentalist rule exceeds the stochastic utility of using an extrapolative rule. In order to derive a more precise expression one has to specify the distribution of the random variables $\varepsilon_{f, t}$ and $\varepsilon_{e, t}$. It is customary in the discrete choice literature to assume that these random variables are logistically distributed (see Anderson, Palma, and Thisse(1992), p. 35). One then obtains the following expressions for the probability of choosing the fundamentalist rule: 


$$
\alpha_{f, t}=\frac{\exp \left(\gamma U_{f, t}\right)}{\exp \left(\gamma U_{f, t}\right)+\exp \left(\gamma U_{e, t}\right)}
$$

Similarly the probability that an agent will use the extrapolative forecasting rule is given by:

$$
\alpha_{e, t}=\frac{\exp \left(\gamma U_{e, t}\right)}{\exp \left(\gamma U_{f, t}\right)+\exp \left(\gamma U_{e, t}\right)}=1-\alpha_{f, t}
$$

Equation (19) says that as the past forecast performance of the fundamentalist rule improves relative to that of the extrapolative rule, agents are more likely to select the fundamentalist rule for their forecasts of the output gap. Equation (20) has a similar interpretation. The parameter $\gamma$ measures the "intensity of choice". It is related to the variance of the random components $\varepsilon_{f, t}$ and $\varepsilon_{e, t .}$. If the variance is very high, $\gamma$ approaches 0 . In that case agents decide to be fundamentalist or extrapolator by tossing a coin and the probability to be fundamentalist (or extrapolator) is exactly 0.5 . When $\gamma=\infty$ the variance of the random components is zero (utility is then fully deterministic) and the probability of using a fundamentalist rule is either 1 or 0 . The parameter $\gamma$ can also be interpreted as expressing a willingness to learn from past performance. When $\gamma=0$ this willingness is zero; it increases with the size of $\gamma$.

It should be mentioned here that the probabilities $\alpha_{f, t}$ and $\alpha_{e, t}$ can also be interpreted as the fractions of agents that use a fundamentalist and extrapolative forecasting rule, respectively. This can be seen as follows. Suppose the number of agents is $N$. Then, if the probability that an agent uses a fundamentalist rule is $\alpha_{f, t}$ , on average $\alpha_{f, t} N$ agents will use this rule. Thus the fraction of the total number of agents using this rule is $\frac{\alpha_{f t} N}{N}=\alpha_{f, t}$. The same holds for $\alpha_{e, t}$. These fractions are determined by the rules (19) and (20) and are time dependent. This illustrates an important feature of the model, i.e. the heterogeneity of beliefs and their shifting nature over time. 
As argued earlier, the selection mechanism used should be interpreted as a learning mechanism based on "trial and error". When observing that the rule they use performs less well than the alternative rule, agents are willing to switch to the more performing rule. Put differently, agents avoid making systematic mistakes by constantly being willing to learn from past mistakes and to change their behavior. This also ensures that the market forecasts are unbiased.

\section{Heuristics and selection mechanism in forecasting inflation}

Agents also have to forecast inflation. A similar simple heuristics is used as in the case of output gap forecasting, with one rule that could be called a fundamentalist rule and the other an extrapolative rule. (See Brazier et al. (2006) for a similar setup). We assume an institutional set-up in which the central bank announces an explicit inflation target. The fundamentalist rule then is based on this announced inflation target, i.e. agents using this rule have confidence in the credibility of this rule and use it to forecast inflation. Agents who do not trust the announced inflation target use the extrapolative rule, which consists extrapolating inflation from the past into the future.

The fundamentalist rule will be called an "inflation targeting" rule. It consists in using the central bank's inflation target to forecast future inflation, i.e.

$$
\widetilde{E}_{t}^{\text {tar }}=\pi^{*}
$$

where the inflation target $\pi^{*}$ is normalized to be equal to 0

The "extrapolators" are defined by

$$
E_{t}^{e x t} \pi_{t+1}=\pi_{t-1}
$$

The market forecast is a weighted average of these two forecasts, i.e.

$$
\widetilde{E}_{t} \pi_{t+1}=\beta_{t a r, t} \widetilde{E}_{t}^{t a r} \pi_{t+1}+\beta_{\text {ext }, t} \widetilde{E}_{t}^{\text {ext }} \pi_{t+1}
$$

or

$$
\begin{aligned}
& \widetilde{E}_{t} \pi_{t+1}=\beta_{t a r, t} \pi^{*}+\beta_{e x t, t} \pi_{t-1} \\
& \text { and } \beta_{t a r, t}+\beta_{e x t, t}=1
\end{aligned}
$$


The same selection mechanism is used as in the case of output forecasting to determine the probabilities of agents trusting the inflation target and those who do not trust it and revert to extrapolation of past inflation, i.e.

$$
\begin{aligned}
& \beta_{t a r, t}=\frac{\exp \left(\gamma U_{t a r, t}\right)}{\exp \left(\gamma U_{t a r, t}\right)+\exp \left(\gamma U_{e x t, t}\right)} \\
& \beta_{e x t, t}=\frac{\exp \left(\gamma U_{e x t, t}\right)}{\exp \left(\gamma U_{t a r, t}\right)+\exp \left(\gamma U_{e x t, t}\right)}
\end{aligned}
$$

where $U_{t a r, t}$ and $U_{\text {ext, } t}$ are the forecast performances (utilities) associated with the use of the fundamentalist and extrapolative rules. These are defined in the same way as in (16) and (17), i.e. they are the negatives of the weighted averages of past squared forecast errors of using fundamentalist (inflation targeting) and extrapolative rules, respectively

This inflation forecasting heuristics can be interpreted as a procedure of agents to find out how credible the central bank's inflation targeting is. If this is very credible, using the announced inflation target will produce good forecasts and as a result, the probability that agents will rely on the inflation target will be high. If on the other hand the inflation target does not produce good forecasts (compared to a simple extrapolation rule) the probability that agents will use it will be small.

\subsection{Defining animal spirits}

The forecasts made by extrapolators and fundamentalists play an important role in the model. In order to highlight this role we define an index of market sentiments, which we call "animal spirits", and which reflects how optimistic or pessimistic these forecasts are.

The definition of animal spirits is as follows:

$S_{t}= \begin{cases}\alpha_{e, t}-\alpha_{f, t} & \text { if } y_{t-1}>0 \\ -\alpha_{e, t}+\alpha_{f, t} & \text { if } y_{t-1}<0\end{cases}$ 
where $S_{t}$ is the index of animal spirits. This can change between -1 and +1 . There are two possibilities:

- When $y_{t-1}>0$, extrapolators forecast a positive output gap. The fraction of agents who make such a positive forecasts is $\alpha_{e, t}$. Fundamentalists, however, then make a pessimistic forecast since they expect the positive output gap to decline towards the equilibrium value of 0 . The fraction of agents who make such a forecast is $\alpha_{f, t}$. We subtract this fraction of pessimistic forecasts from the fraction $\alpha_{e, t}$ who make a positive forecast. When these two fractions are equal to each other (both are then 0.5) market sentiments (animal spirits) are neutral, i.e. optimists and pessimists cancel out and $S_{t}=0$. When the fraction of optimists $\alpha_{e, t}$ exceeds the fraction of pessimists $\alpha_{f, t} S_{t}$ becomes positive. As we will see, the model allows for the possibility that $\alpha_{e, t}$ moves to 1 . In that case there are only optimists and $S_{t}=1$.

- When $y_{t-1}<0$, extrapolators forecast a negative output gap. The fraction of agents who make such a negative forecasts is $\alpha_{e, t}$. We give this fraction a negative sign. Fundamentalists, however, then make an optimistic forecast since they expect the negative output gap to increase towards the equilibrium value of 0 . The fraction of agents who make such a forecast is $\alpha_{f, t}$. We give this fraction of optimistic forecasts a positive sign. When these two fractions are equal to each other (both are then 0.5) market sentiments (animal spirits) are neutral, i.e. optimists and pessimists cancel out and $S_{t}=0$. When the fraction of pessimists $\alpha_{e, t}$ exceeds the fraction of optimists $\alpha_{f, t}$ $S_{t}$ becomes negative. The fraction of pessimists, $\alpha_{e, t}$, can move to 1 . In that case there are only pessimists and $S_{t}=-1$.

We can rewrite (28) as follows²:

\footnotetext{
${ }^{2}$ In De Grauwe(2012) animal spirits are defined so as to move between 0 and 1. It can be shown that the animal sprits defined here are the same apart from a linear transformation that allows the animal sprits index to move between -1 and +1 .
} 


$$
S_{t}=\left\{\begin{array}{cl}
\alpha_{e, t}-\left(1-\alpha_{e, t}\right)=2 \alpha_{e, t}-1 & \text { if } y_{t-1}>0 \\
-\alpha_{e, t}+\left(1-\alpha_{e, t}\right)=-2 \alpha_{e, t}+1 & \text { if } y_{t-1}<0
\end{array}\right.
$$

\subsection{Solution of the model}

The solution procedure of the model is described in appendix 1 . As the model is highly non-linear we calibrate it and use numerical methods to solve it. The table with the numerical values given to the coefficients is presented in appendix 2 . We will perform extensive sensitivity analysis to check the robustness of our results.

\section{Results of the model: the basics}

In this section we present some of the basic results of simulating the model using the calibration discussed in the previous section. We present the results both for the monetary union model (one central bank) and the monetary independence model (two-country model with separate central banks).

\subsection{Monetary union model}

We first present the results of the simulation exercises in the time domain. This will allow us to understand the dynamics produced by the model. In the next sections we perform sensitivity analyses. Figure 2 presents the simulated output gaps in the two countries. We find a relatively high correlation of these output gaps between the two countries. This correlation is 0.95 . Underlying this is an import propensity $(\mathrm{m})$ of 0.3 and a correlation of the exogenous demand shocks of 0.2 . Thus the model produces a synchronization of the business cycle that adds to the trade integration effect and the existence of correlation of the exogenous demand shocks. The additional synchronization comes from "the animal spirits". These are shown in figure 3. As explained in the previous section, the "animal spirits" measure market sentiments, i.e. optimism and pessimism in forecasting. We observe that the model produces waves of optimism and pessimism that can lead to a situation where everybody becomes optimist $\left(S_{t}=1\right)$ or pessimist 
$\left(S_{t}=-1\right)$. These waves of optimism and pessimism are generated endogenously and arise because optimistic (pessimistic) forecasts are self-fulfilling and therefore attract more agents into being optimists (pessimists).

The correlation of these animal spirits and the output gap is high. In the simulations reported in figure 3 this correlation reaches 0.94 . Underlying this correlation is the self-fulfilling nature of expectations. When a wave of optimism is set in motion, this leads to an increase in aggregate demand (see equation 1). This increase in aggregate demand leads to a situation in which those who have made optimistic forecasts are vindicated. This attracts more agents using optimistic forecasts. This leads to a self-fulfilling dynamics in which most agents become optimists.

The reverse is also true. A wave of pessimistic forecasts can set in motion a selffulfilling dynamics leading to a downturn in economic activity (output gap). At some point most of the agents have become pessimists.

It now appears that the model produces an international contagion of animal spirits. This is seen from the same figure 3 showing the animal spirits in both countries. These animal spirits are highly correlated between the two countries reaching 0.95 . The mechanism that produces this can be described as follows. When a wave of optimism is set in motion in country 1 , it leads to more output and imports in that country, thereby increasing output in country 2 . This positive transmission, even if small, makes it more likely that agents in country 2 that make optimistic forecasts are vindicated, thereby increasing the fraction of agents in country 2 that become optimists. Thus we obtain a transmission dynamics that although triggered by trade flows is amplified and leads to a strong synchronization of the business cycles across countries.

The previous analysis has identified the dynamics that leads to strong synchronization of the business cycle across countries in a monetary union. This dynamics is based on the international contagion of optimism and pessimism (animal spirits) in a monetary union. Is this contagion also present in countries that have a separate currency and their own central bank? This question is discussed in the next section. 
Figure 2: simulation of the output gaps in countries 1 and 2
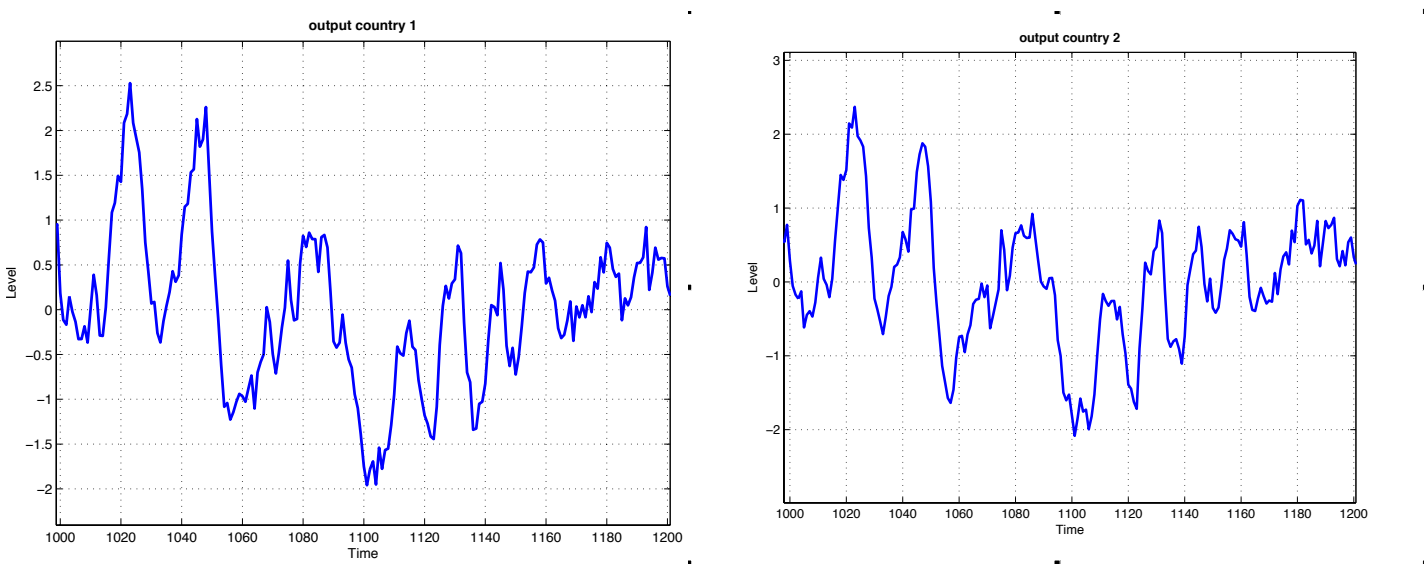

Figure 3: simulation of the animal spirits in countries 1 and 2
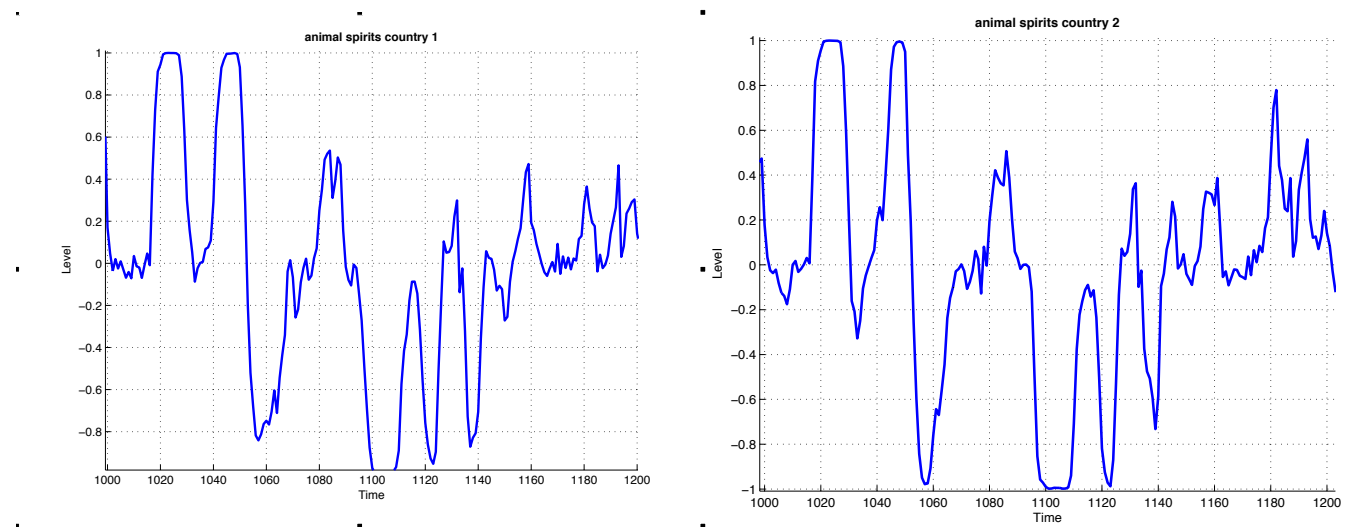

Note: the correlation across the two countries is 0.94

\subsection{Monetary independence model}

In this section we present the result for the two-country model with two independent central banks. In figures 5 and 6 we present the results of simulating the model assuming two currencies and two separate central banks. Figure 5 shows the movements of the output gaps in the two countries and figures 6 the animal spirits in these two countries. We observe a similar dynamics as in the previous section. The correlation between the output gaps in the two countries, however, is smaller, i.e. 0.73 (versus 0.95 in the previous section). This has to do with the lower correlation of animal spirits between the two countries, i.e. 0.70 , (versus 0.94 in the previous section). Nevertheless it is interesting to find that the behavioral model also produces a strong 
synchronization of the business cycles across countries that have maintained their own currencies.

Figure 5: simulation of the output gaps in countries 1 and 2
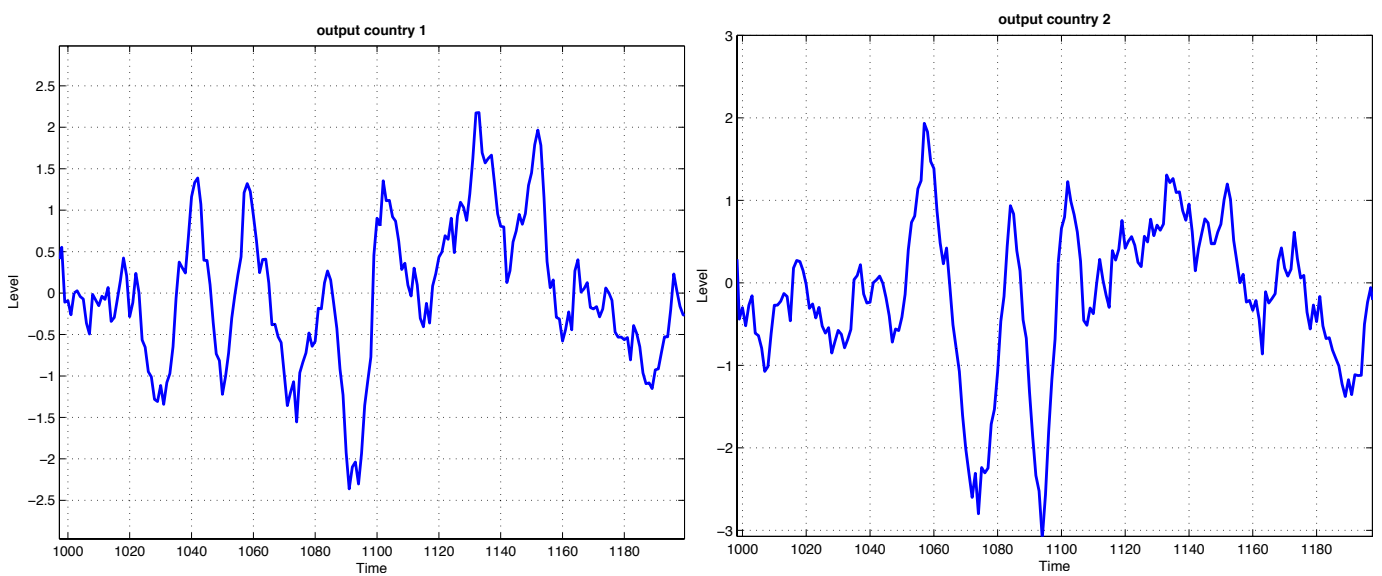

Figure 6: simulation of the animal spirits in countries 1 and 2
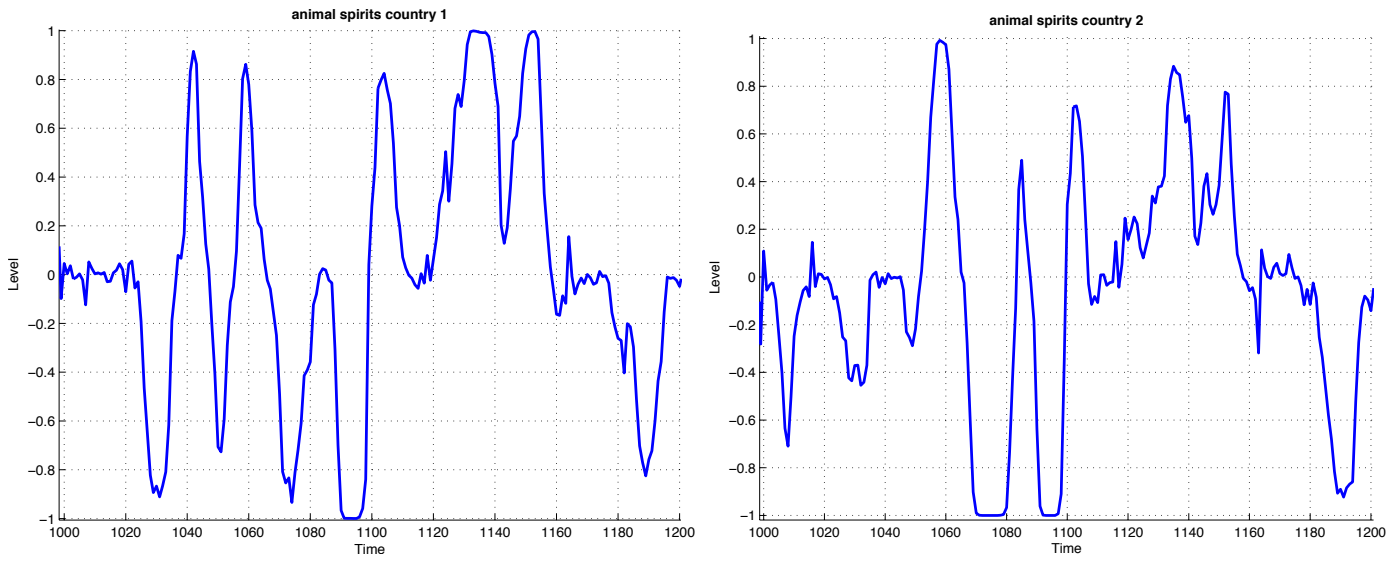

It should be mentioned that we produce simulation results assuming the same parameter values of the model. In particular, we assume the same degree of trade integration and the same correlation of the exogenous shocks. Thus, the lower correlation of output gaps obtained here must be due to other factors. We will show in the next section that the difference in correlation of output gaps and animals spirits across countries has to do with the existence of one central bank in the monetary union model, and two central banks in the second model. 


\section{Results of the model: factors affecting synchronization of business cycle}

In this section we analyze the factors that influence the synchronization of the business cycles across countries. We do this by presenting sensitivity analyses, i.e. we study how the correlations of the output gaps between the two countries are influenced by a number of important parameters of the model. We will focus on trade integration, the correlations of exogenous shocks, and the degree of stabilization of the output gap by the common central bank. We do this for the two models, i.e. monetary union and separate central bank.

\subsection{Monetary union model and trade integration}

We first focus on how trade integration (measured by the import propensities, $m$ ) affects the correlation of output gaps and animal spirits across countries. We show the results in figures 7 and 8 . On the horizontal axis we set out the import propensities and allow it to change from 0 to 1 . On the vertical axis we set out the correlation of output gaps between the two countries (figure 7) and the correlation of animal spirits (figure 8) that we obtain in the model for each value of $m$. We find strikingly that even when there is no trade between the two countries $(m=0)$ the model produces positive correlations of output gaps and animal spirits. As trade integration increases the degree of correlation increases. This relation is highly non-linear. When $m$ increases the correlations increase very fast and then level off for values of $m$ equal to approximately 0.4 . Further trade integration has very little additional impact on the synchronization of the business cycles.

Two results stand out here. First the fact that even in the absence of trade there is some synchronization of the business cycles and of animal spirits. This has to do with the fact that underlying this result is a positive correlation of exogenous demand shocks (0.2). We discuss the importance of varying this parameter in the next section.

The other interesting result is the non-linear relation between the intensity of trade and the synchronization of the business cycles. Most of the synchronization is reached for relatively low levels of trade integration. Thus relatively low levels 
of trade are enough to trigger the contagion of animal spirits and through this channel the synchronization of the business cycles. This may explain why we do not find that among a group of highly integrated industrial countries increasing integration has only weak effects on the correlation of output (see figures $2 \& 3$ ).

\section{Figure 7: Correlation of output gaps and import propensities}

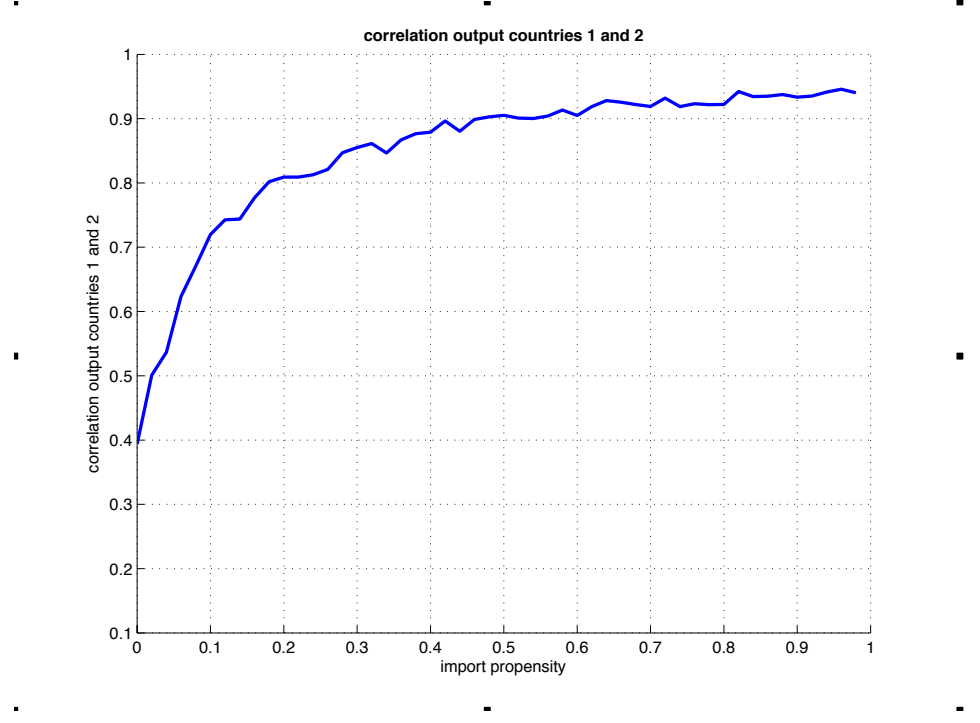

Figure 8: Correlation of animal spirits and import propensities

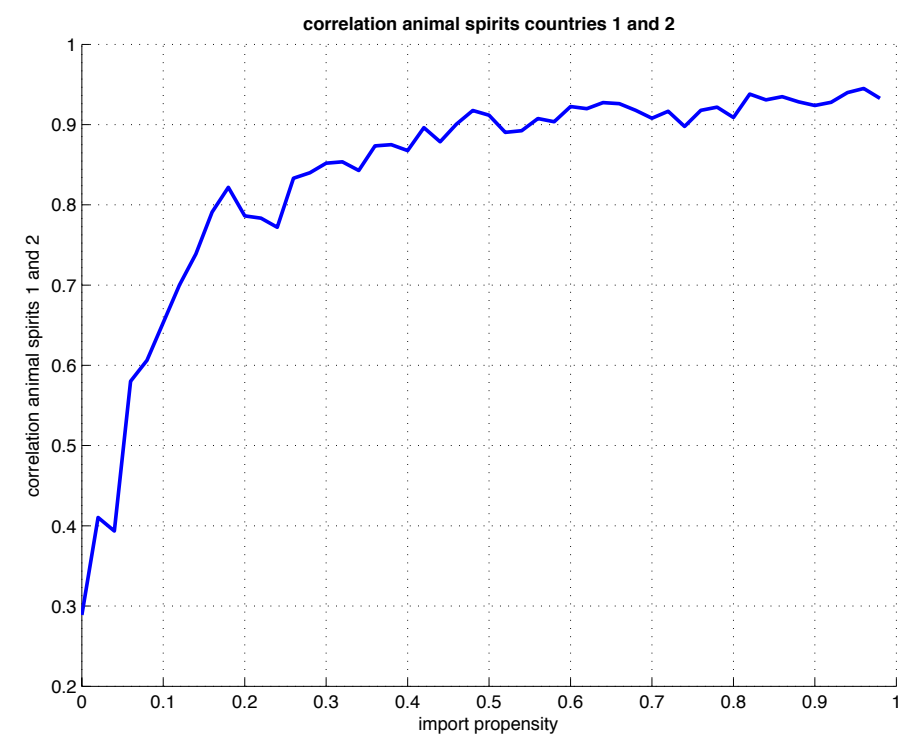

\subsection{Monetary independence model and trade integration}

Figures 9 and 10 show the results of the sensitivity of the synchronization of the business cycle with respect to trade integration in the two country model with 
two central banks. The results are qualitatively similar to the results in a monetary union, i.e. the non-linear relation between synchronization and import propensity. The difference lies in the fact that for each value of $m$ the corresponding correlation is lower than in the monetary union case.

Figure 9: Correlation of output gaps and import propensities

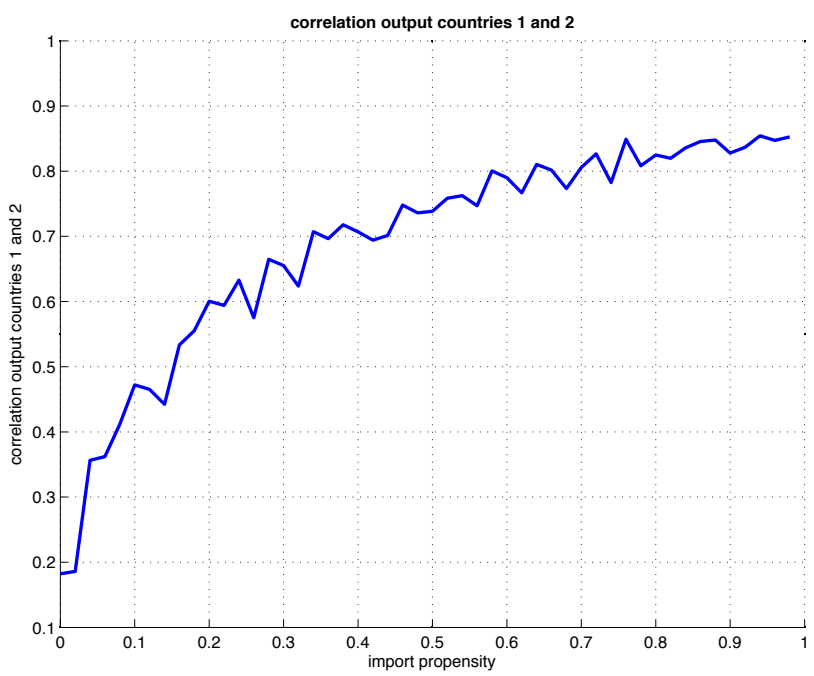

Figure 10: Correlation of animal spirits and import propensities

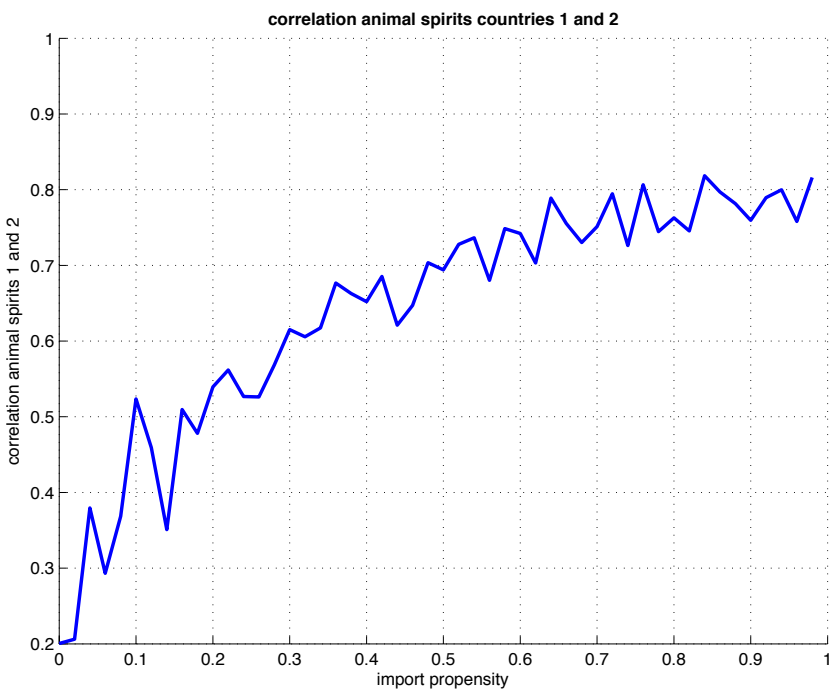




\subsection{Synchronization of business cycles and correlation of shocks}

Figures 11 and 12 show the sensitivity of the synchronization of business cycles to the correlation of shocks in the monetary union (left panels) and in the monetary independence model (right panels). We assume shocks both in the demand and supply equations. We vary the correlation between -1 and +1 . The vertical axes as before show the correlations of output gaps and animal spirits across countries.

The most surprising aspect of these results is that with a perfectly negative correlation of the shocks, the correlation of animal spirits is still positive (approximately 0.4) in a monetary union. As a result, the correlation of output gaps is not -1 (as one may have expected), but approximately -0.4 . Where does this come from? The answer is the existence of one central bank. The latter sets an interest rate that is the same for both countries according to the Taylor rule. This interest rate setting relation is also subject to random shocks. But since the same rule applies to both countries one has a source of common shocks in these two countries. This then allows animal spirits to be positively correlated even if all the other shocks are negatively correlated.

In both cases we observe again a non-linearity in the relation between correlation of shocks and the correlation of the output gaps. This non-linearity is most pronounced in the monetary union: small declines in the (negative) correlation of the shocks leads to a quick increase in the synchronization of the business cycles (correlation of output gaps). As a result, with a correlation of shocks equal to 0 the correlation of output gaps reaches 0.8 (see figure 11).

This feature is less pronounced in the model of two countries with two central banks (right panels). With correlation of shocks equal to 0 the correlation of output gaps is positive but lower than in the monetary union. It reaches about 0.5. This difference has to do with the fact that in this model two central banks set their own interest rate thereby eliminating a source of common shock. 
Figure 11: correlation output and correlation of shocks

Monetary union

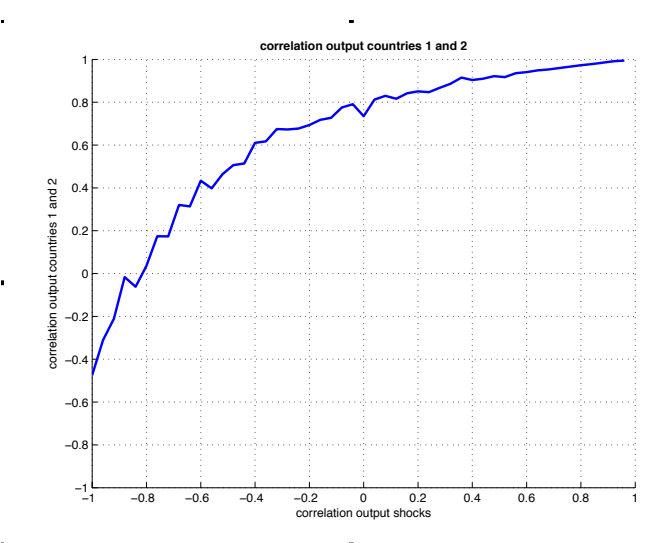

Monetary independence

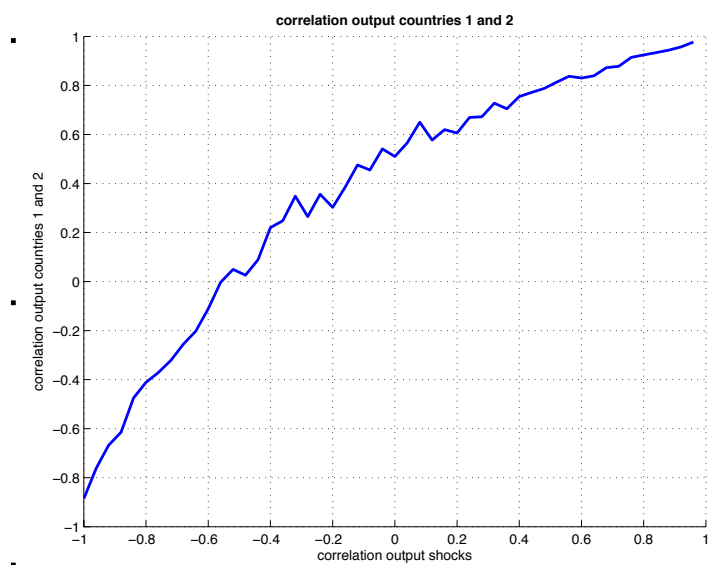

Figure 12: correlation animal spirits and correlation shocks

Monetary union

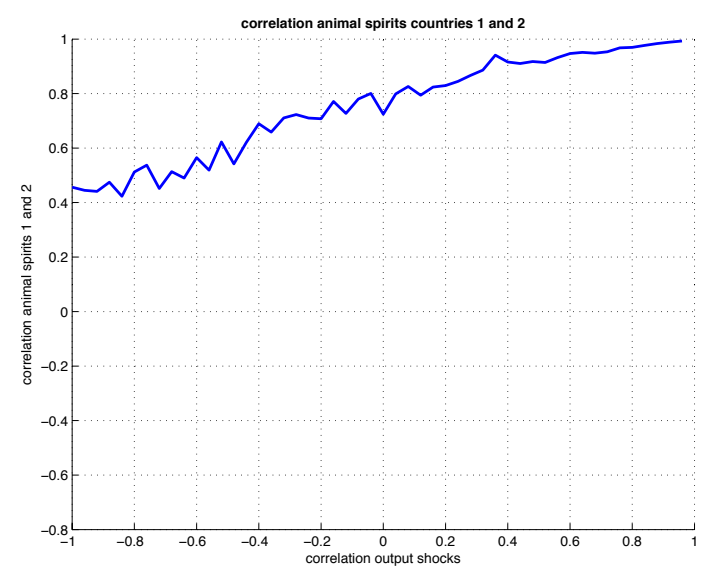

Monetary independence

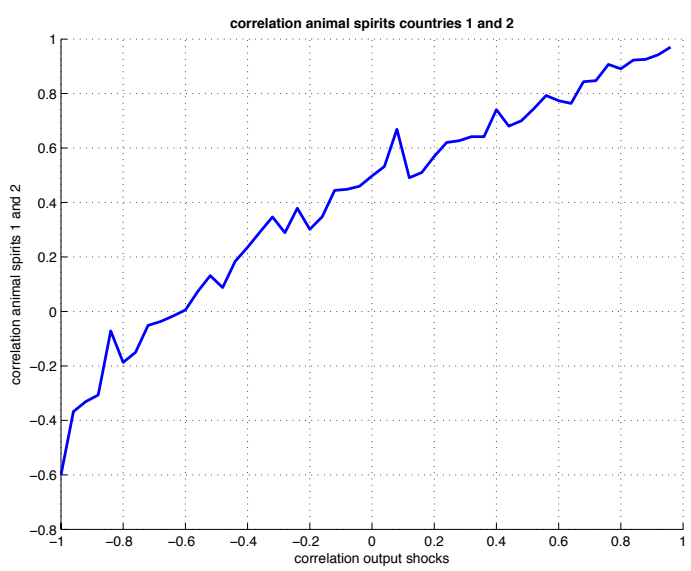

\subsection{Synchronization of business cycles and output stabilization}

The degree of output stabilization exerted by the central bank has important effects on the emergence of animal spirits in our behavioral model. We showed earlier (De Grauwe(2012)) that by a more forceful output stabilization (as measured by the coefficient $c_{2}$ in the Taylor rule equation), the central bank can reduce the intensity of the movements in animal spirits. Given the importance of animal spirits in propagating business cycles from one country to the other, the central bank's stabilization efforts can have a significant impact on this propagation. We analyze this issue here. 
We do this by studying the sensitivity of the correlations of the output gaps and animal spirits with respect the output coefficient $c_{2}$ in the Taylor rule. We do this for both the monetary union model and the model with two central banks. The results are shown in figures 13 and 14 . We allow the Taylor output parameter $\left(\mathrm{c}_{2}\right)$ to vary from 0 to 2 (horizontal axes) and compute the corresponding correlations of the output gaps (figure 13) and animal spirits (figure 14).

\section{Figure 13: synchronization of business cycles and stabilization effort}

Monetary union

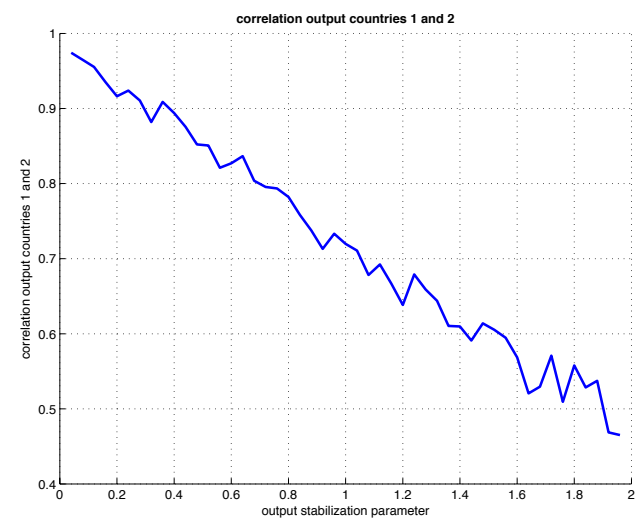

Monetary independence

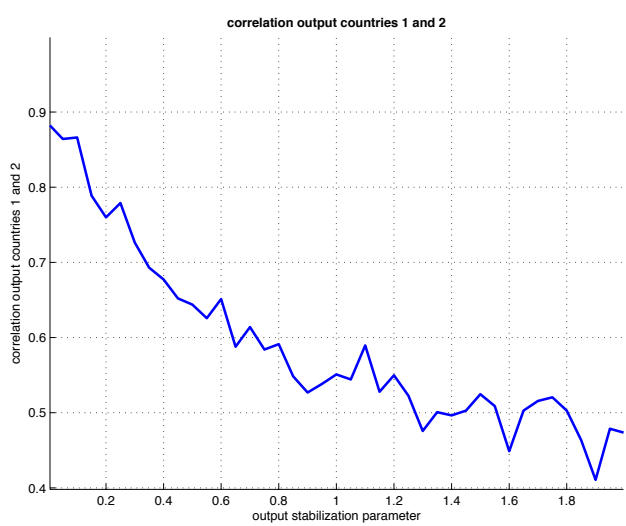

Figure 14: synchronization of animal spirits and stabilization effort

Monetary union

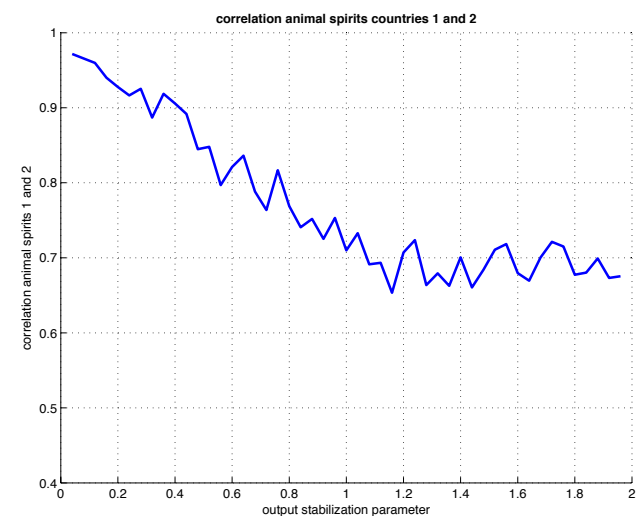

Monetary independence

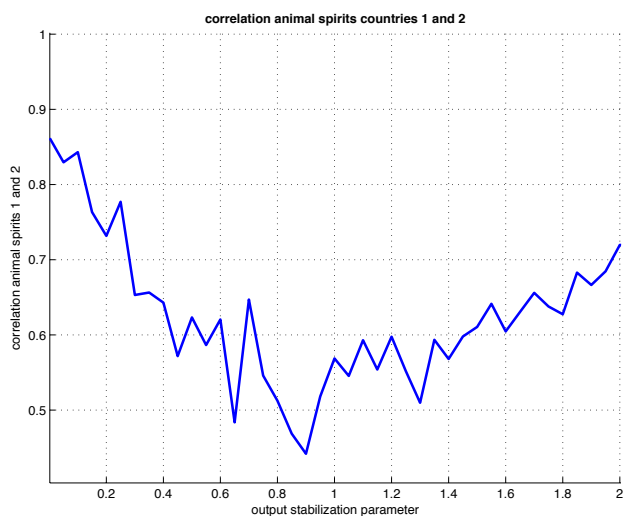

The results confirm the importance of output stabilization for the international propagation of business cycles. In general when the central bank increases its effort to stabilize output ( $c_{2}$ increases) the correlation of the output gaps across countries declines. Not surprisingly this effect is strongest in the model of 
monetary independence. The reason is that in this model the existence of two central banks increases their effectiveness in "taming the animal spirits". As a result the international propagation of these animal spirits is also reduced. This leads to less synchronization of the business cycles.

\section{International transmission of demands shocks}

In this section we analyze how a demand shock in country 1 (that is produced by e.g. a fiscal policy stimulus) is transmitted to country 2 . We do this first for the monetary union. In the section 5.2 we focus on the model with 2 central banks.

\subsection{Monetary union regime}

We compute impulse responses to the shock both for output in country 1 and country 2. These impulse responses are expressed as "multipliers", i.e. the output responses to the shock are divided by the shock itself (which is one standard deviation of the error term in the demand equation of country 1 ).

In contrast to linear rational expectations models the impulse responses depend on the timing of the shock. Put differently, an impulse response computed with one realization of the stochastic shocks in the demand and supply equations of the model will be different from an impulse response to exactly the same shock but performed using another realization of these stochastic shocks. This is the case even when all parameters of the model are identical. We illustrate this by presenting two impulse responses of the output gap in country 2 to a demand shock occurring in country 1 (Figures 15 and 16). These are obtained with exactly the same parameters but with different realizations of the stochastic shocks in the model. Thus it appears that it will be very difficult to predict the transmission of the demand shock from one country to the other, as this transmission depends on "initial conditions", i.e. on the configuration of stochastic disturbances that prevail at the moment the demand shock occurs. 
Figure 15: Impulse responses of output to demand shock in country 1

Country 1

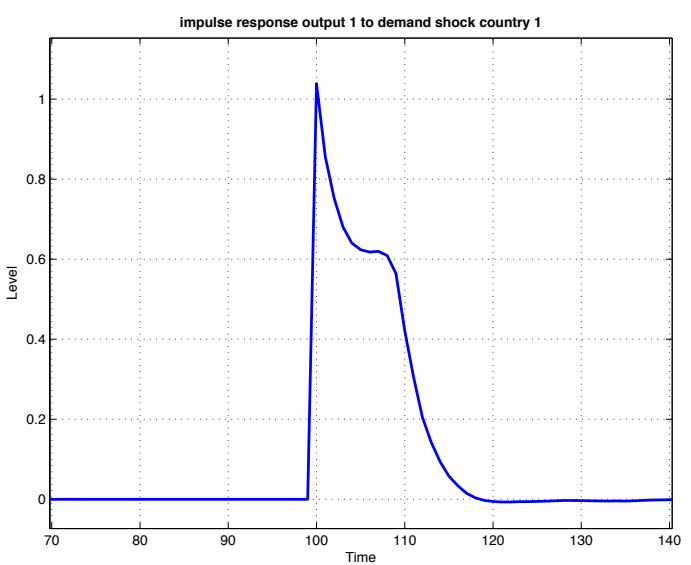

Country 2

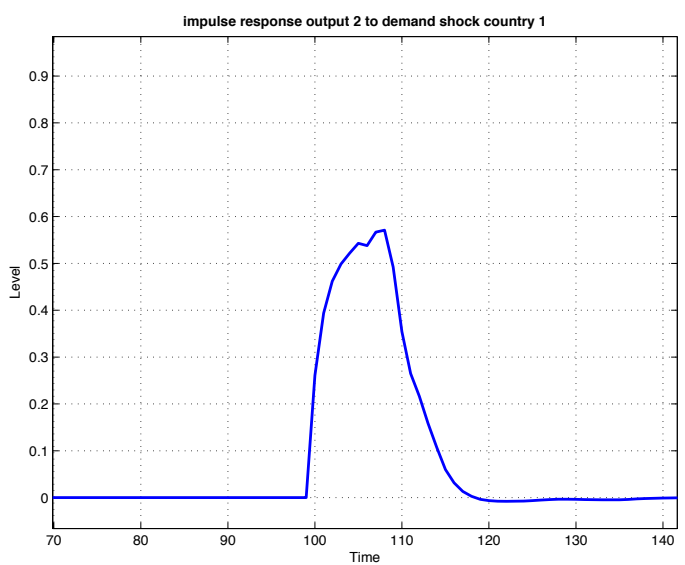

Figure 16: Impulse responses of output to demand shock in country 1

Country 1

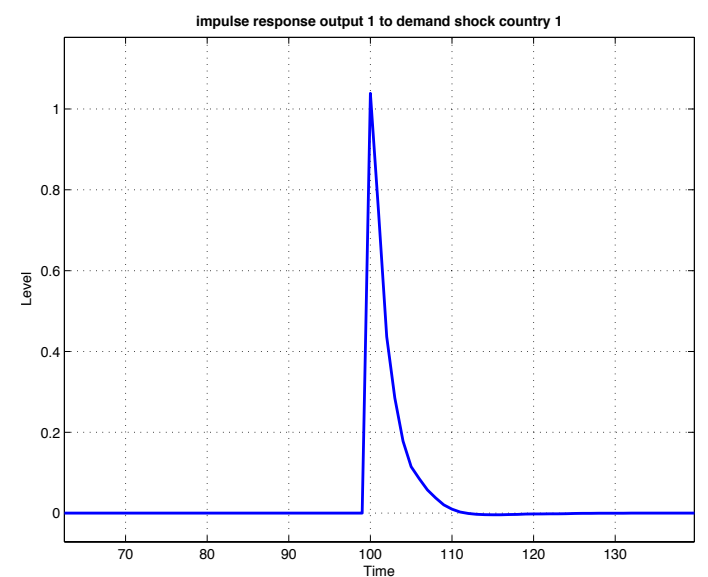

Country 2

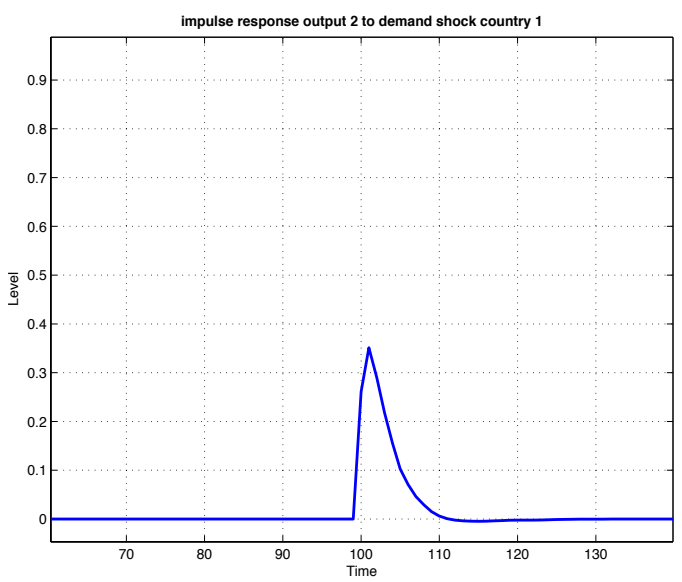

Note: $\mathrm{c}_{2}=0.2$

This result can be made even more precise by presenting the frequency distribution of the short-term effects of the demand shock in country 1 . This frequency distribution was derived as follows. We simulated 1000 impulse responses to the same demand shock in country 1, assuming each time a different realization of stochastic shocks. We then collected the impulse response obtained in the $2^{\text {nd }}$ period after the demand shock occurred. In so doing we obtained 1000 short-term output responses. We plot these in the frequency domain. The results are shown in Figure 17. We find an extreme variation of these output responses both in country 1 and country 2 . To repeat, this variation 
is only related to the fact that the 1000 simulations of the demand shock in country 1 occur with different "initial conditions" (different realizations of stochastic shocks). Thus, it matters a great deal when the demand shock occurs. For example, the effect of the demand shock in country 1 may be very different depending on whether the shock occurs during a recession, a boom or in more normal business cycle conditions. In order to obtain further insight in this question we plotted the short-term output responses in country 2 against the animal spirits in country 2 prevailing at the time of the demand shock in country 1. We present the results in figure 18. The results are quite interesting. We observe that when the animal spirits are around 0 , which means that there is no optimism or pessimism (there is "Great Moderation"), the transmission of demand shocks from country 1 to country 2 are small. On average the multipliers are around 0.2. However, when the economy is gripped by extreme optimism (leading to a boom) or to extreme pessimism (leading to a recession) the transmission of the same shock in country 1 to country 2 becomes much larger. On average the multipliers double to approximately 0.4 .

Figure 17: Short-term output responses to demand shock in country 1

Country 1

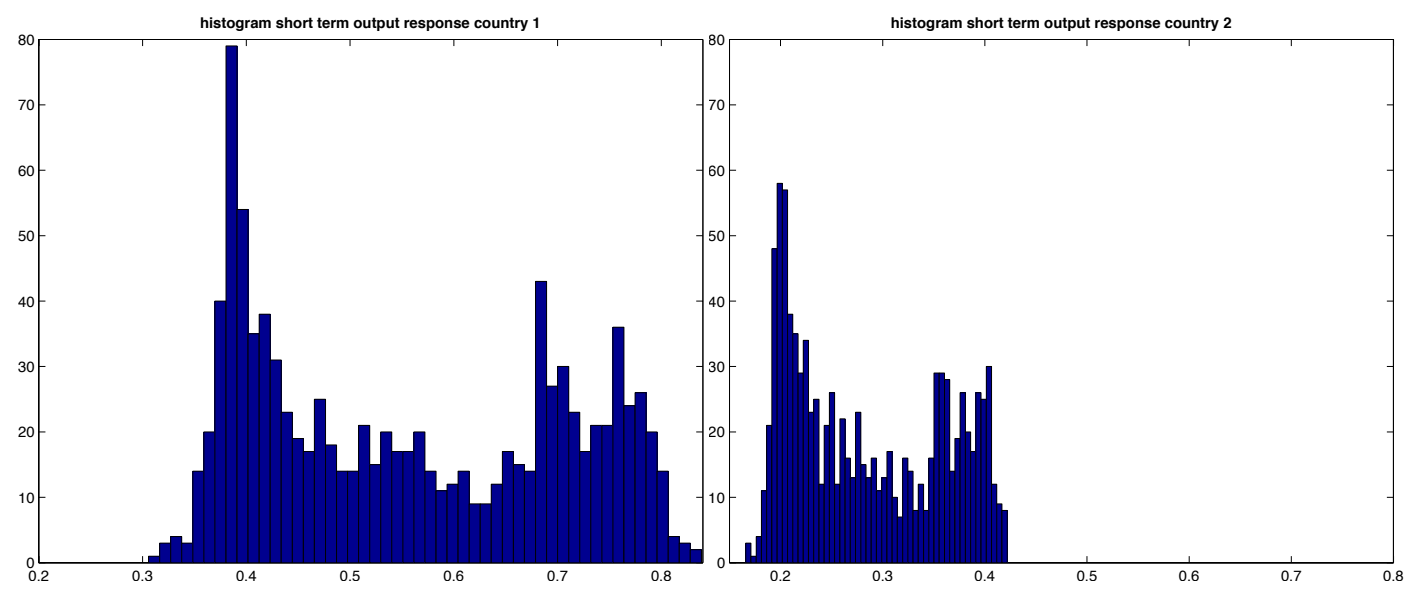




\section{Figure 18: Short-term output responses and animal spirits}

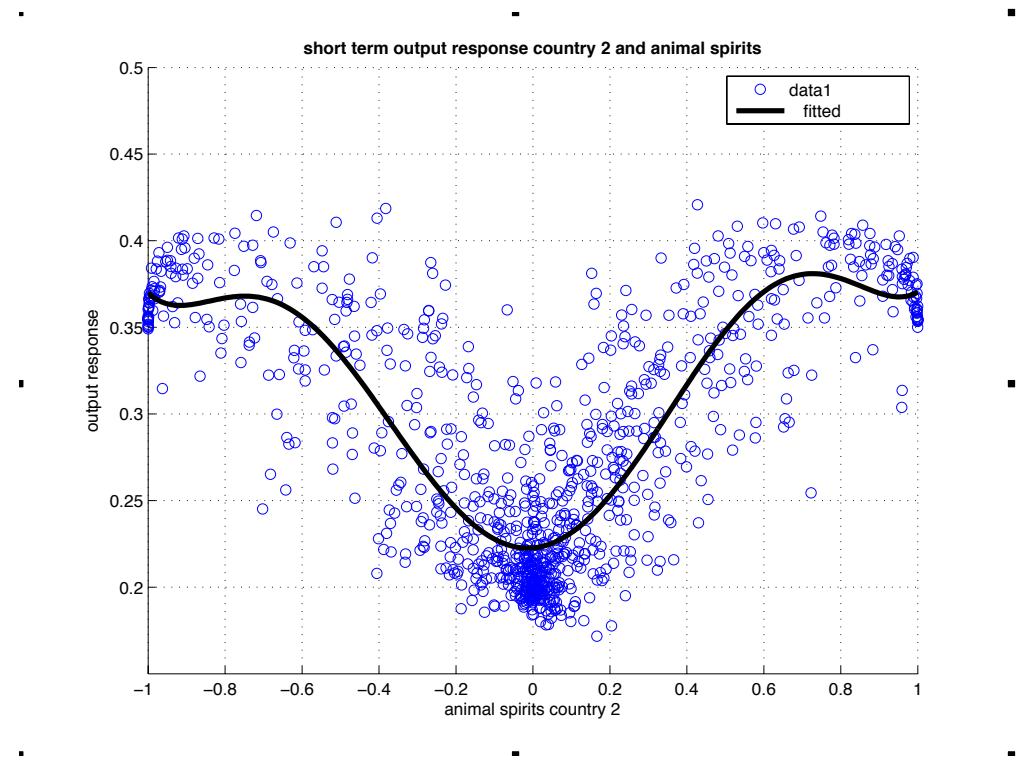

This result suggests that during periods of recession, like the one the Eurozone has experienced since the debt crisis of 2010, a fiscal expansion in one country, say Germany, can have a much higher impact on the other Eurozone countries than in normal times. A word of caution, however, is appropriate. We observe from figure 18 that there is a lot of variation around the mean effect shown by the quadratic line.

How often do these extreme situations of pessimism and optimism occur? The answer is given in figure 19. This presents the frequency distribution of animal spirits in country 2 (in the same simulation as figure 18). We observe that normal times (periods during which animal spirits cluster around 0) are more frequent than extreme times when animal spirits cluster around -1 or 1 . In our simulations periods of extreme pessimism occur approximately $10 \%$ of the time; similarly periods of extreme optimism occur about $10 \%$ of the time. Put differently, during normal and relatively quiet times when market sentiments are neutral, the transmission of demand shocks is also subdued. In times of strong optimism of pessimism this transmission is enhanced. This are also the moments during which business cycles are strongly correlated. 
Figure 19: Frequency distribution of animal spirits in country 1

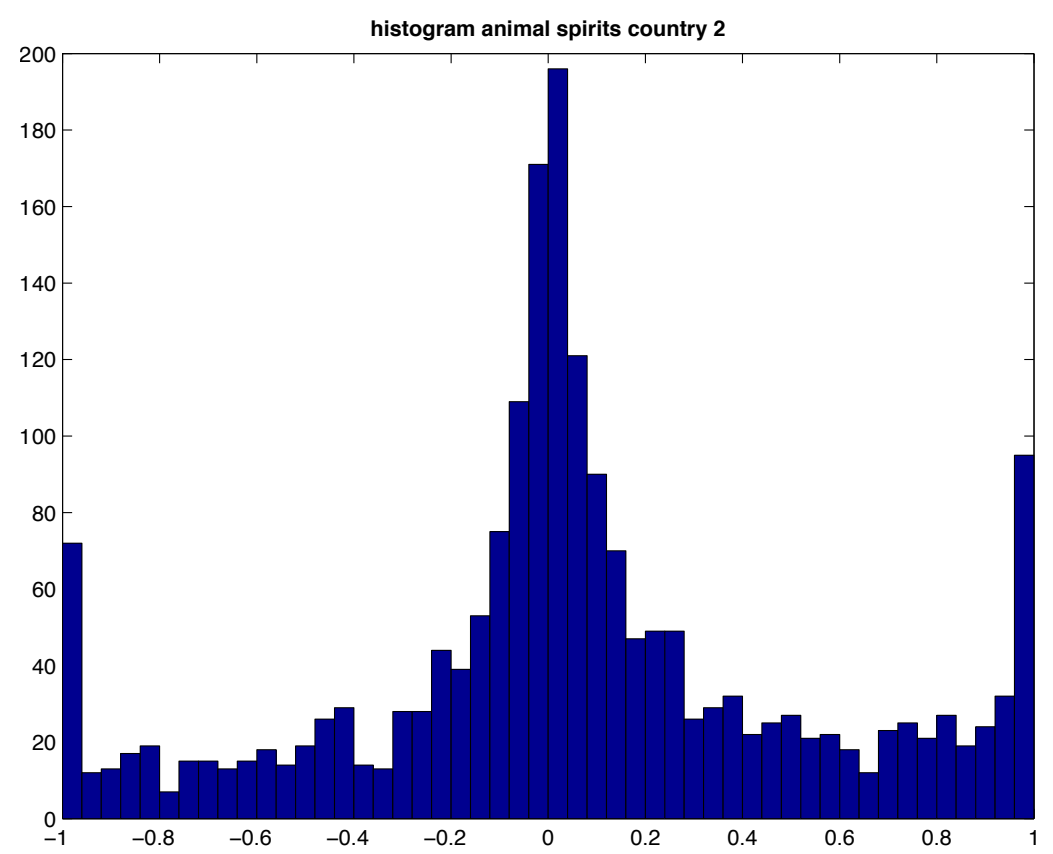

The previous simulations were performed using the standard set of parameters. It is important to also shed light on the sensitivity of these results to changes in the parameters of the model. That is what we do now.

We first concentrate on the sensitivity to import propensity. We show a simulation of the short-term output effects in country 2 for increasing values of the import propensity, which we allow to increase from 0 to 0.6 . The results are shown in figure 20. Not surprisingly the transmission of the demand shock in country 1 increases with the propensity to import. Here again we observe that this relation is non-linear, i.e. the increases in the transmission are fastest when import propensities are low. At some level more trade integration has little further effects on this transmission.

The second parameter we focus on here is the degree of output stabilization by the common central bank. We show the results in figure 21. This presents the output responses in country 2 as a function of the Taylor output parameter $c_{2}$. The degree of output stabilization applied by the common central bank appears to have a very strong effect on the transmission of the demand shock. As the central bank applies more stabilization ( $c_{2}$ increases) the output responses in country 2 to the demand shock in country 1 decline significantly. This result is 
related to what we found earlier when we analyzed the correlations of the output gaps across countries. When the central bank applies a lot of output stabilization it "tames animal spirits". This then weakens the transmission of shocks because it weakens the amplification dynamics produced by animal spirits. Note also that when the central bank applies a lot of output stabilization ( $\mathrm{c}_{2}$ is high) the volatility around the mean output response declines. With low $\mathrm{c}_{2}$ this volatility (and therefore uncertainty) of the output responses is very high. This has to do with the fact that each simulation is performed with different realizations of the stochastic shocks in the model.

\section{Figure 20}

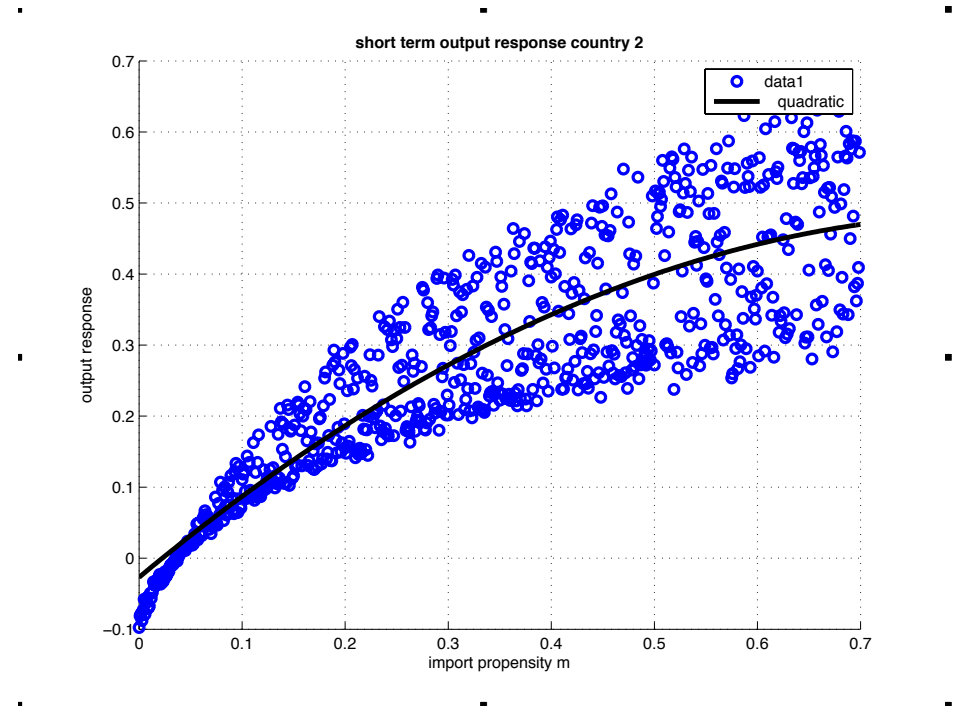

Figure 21.

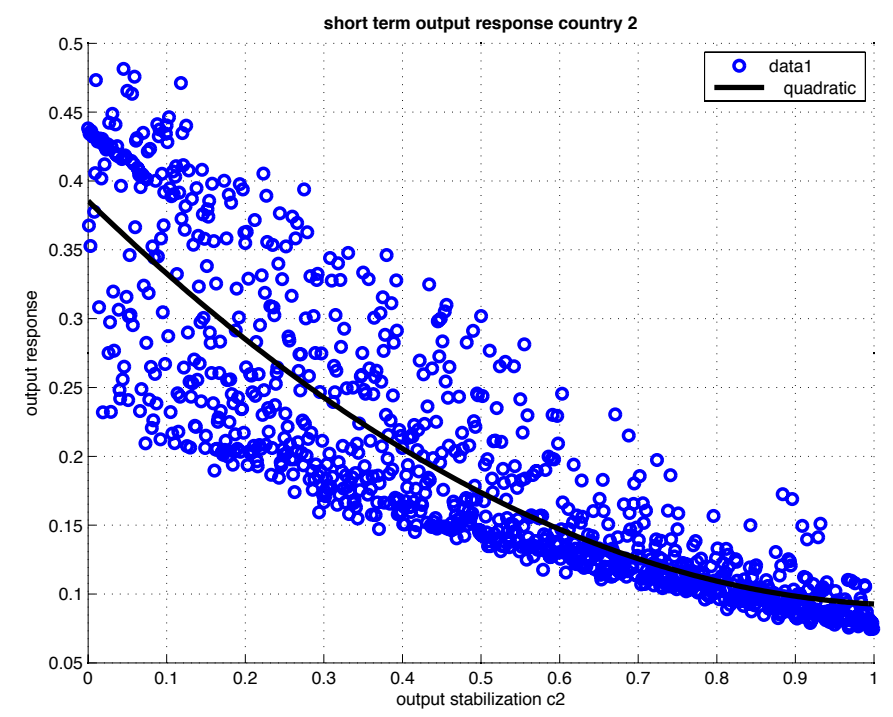


There has been a lot of empirical analysis on the size of the output coefficient $c_{2}$ in the Taylor rule. In Blattner and Margaritov(2010), using many different specifications of the Taylor rule, this coefficient was estimated to be 0.2 on average ${ }^{3}$.

\subsection{Monetary independence}

In this section we report the results of impulse responses of output in country 1 to a demand shock in country 1 when these two countries have their own central banks. We will focus on the differences with the results obtained in the previous section. We show the results in figures 22 to 25 . We observe that the results are qualitatively very similar to those obtained in the monetary union regime. Thus, the transmission of a demand shock from one country to the other does not seem to be very much different from the transmission inside a monetary union. More research, however, is necessary to find out whether this conclusion also holds when the exchange rate transmission process is taken into account.

Figure 22: Short-term output responses to demand shock in country 1 (2 central banks)

Country 1

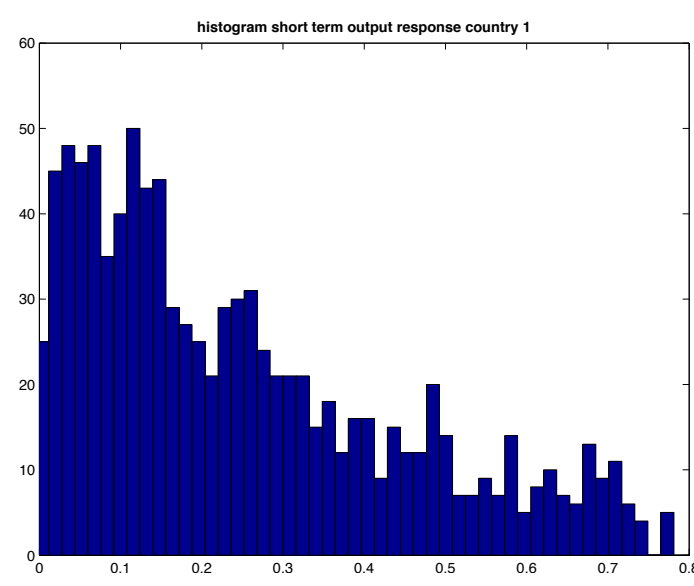

Country 2

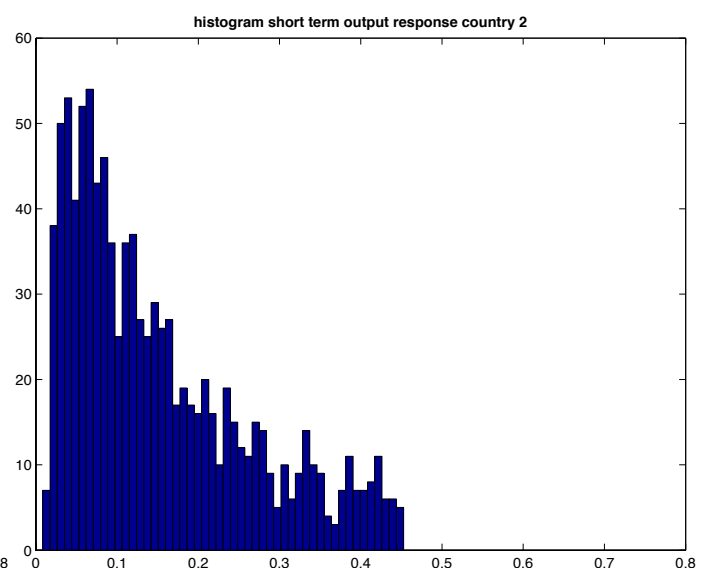

3 The specification of the Taylor rule in Blattner and Margaritov(2010) is somewhat different from the specification used here. Our parameter $c_{2}$ corresponds to $(1-\rho) \beta$ in Blattner and Margaritov(2010). The latter find a mean value for $\beta$ of 1 . This corresponds to a mean value of $c_{2}=0.2$ (given that in our model $\rho$ (the interest smoothing parameter $)=0.8$ ) 
Figure 23: Short-term output responses and animal spirits ( 2 central banks)

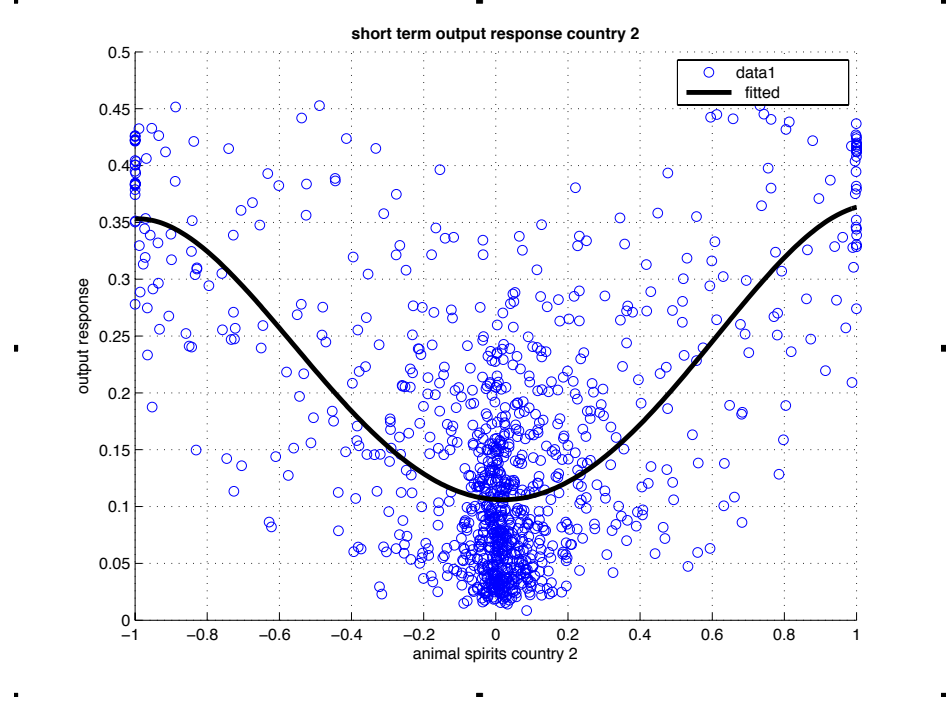

Figure 24

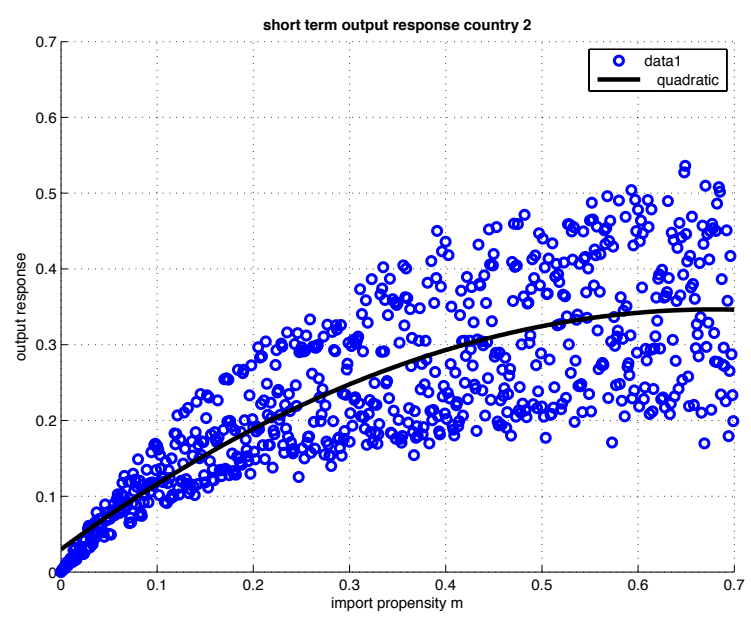

Figure 25

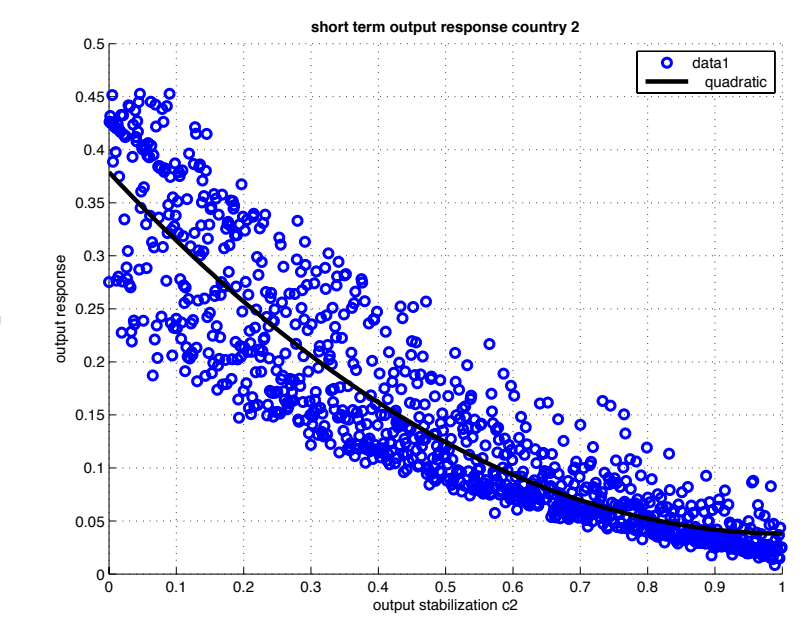




\section{Transmission of supply shocks}

We analyze how a supply shock occurring in country 1 is transmitted in countries 1 and 2. We first focus on a monetary union and then on monetary independent countries.

\subsection{Monetary union}

We show the frequency distribution of the short-term output effects in countries 1 and 2 in Figure 26. The most surprising aspect of these results is that the negative supply shock of country 1 has a stronger negative effect on output of country 2 than on output of country 1 . The reason we obtain this result is the following. The negative supply shock of country 1 has a strong positive effect on country 1's inflation rate and a weak effect on country 2's inflation. The common central bank has to set one common interest rate which will reflect the average inflation rate in the union. As a result, the real interest rate tends to decline in country 1 and to increase in country 2 . This in turn tends to stimulate demand in country 1 , and to reduce demand in country 2 . Thus we see that the supply shock in country 1 tends to be transmitted to country 2 in the form of a strong reduction of aggregate demand. This effect can be decomposed into two. First, the negative supply shock in country 1 reduces that country's demand for country 2's goods. Second the reaction of the common central bank to raise the common interest rate raises the real interest rate in country 2 and amplifies the negative demand shock coming from country 1 . The upshot is that country 1's negative supply shock is transformed into a negative demand shock in country 2. As we will see this effect disappears in a regime where country 2 has its own central bank.

In Figure 27 we plot the short term output effects in country 2 against the animal spirits in country 2 . We observe a similar phenomenon as noted in the previous section. The size of the transmission of the supply shock depends on the intensity of the animal spirits. When these are extreme (positive of negative) the negative output effects in country 2 are significantly higher than when market sentiments are neutral. 
Figure 26: Short-term output responses to supply shock in country 1

Country 1

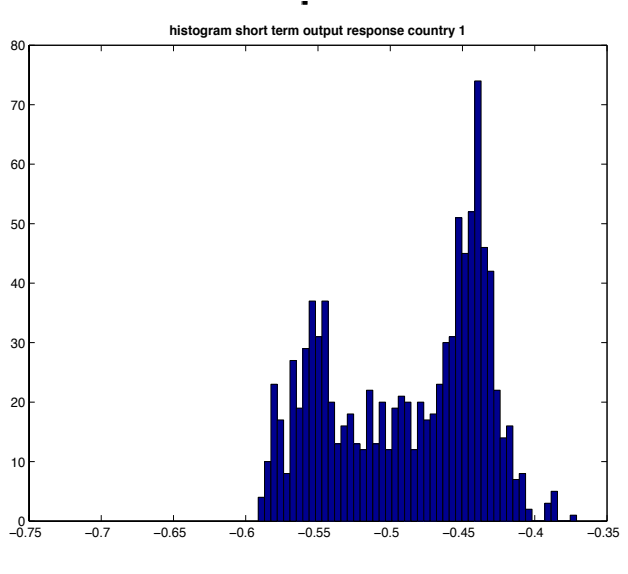

Country 2

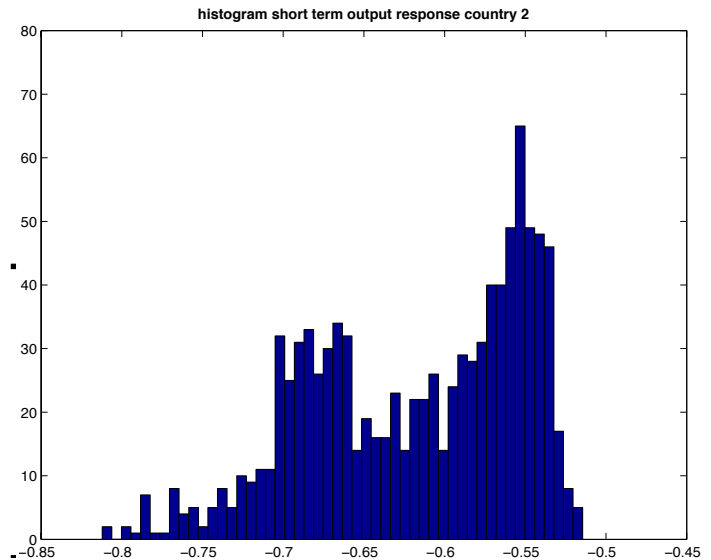

Figure 27

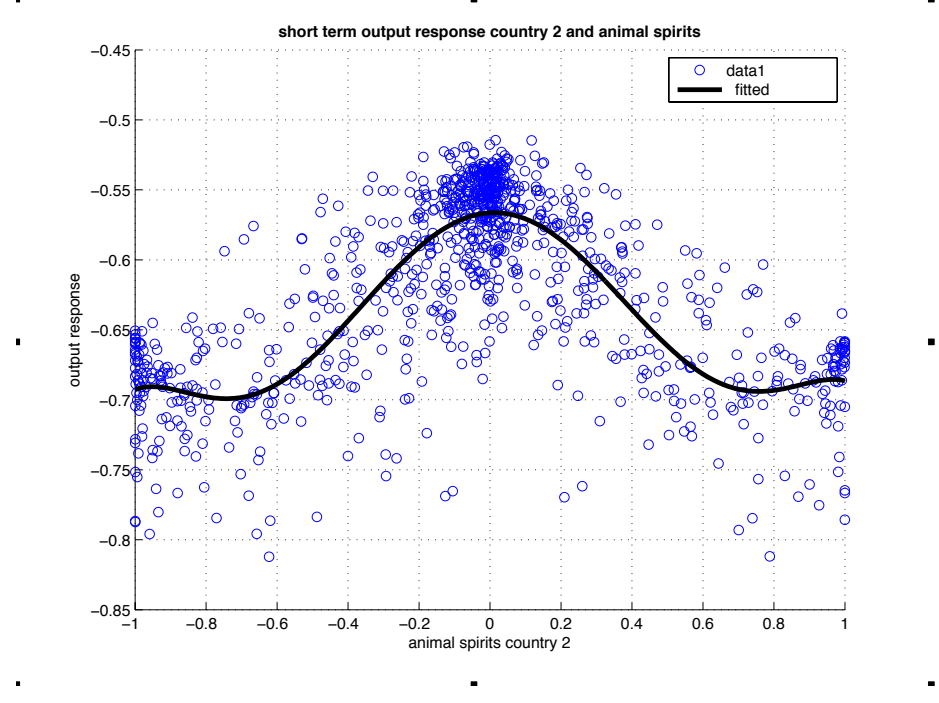

\subsection{Monetary independence}

In Figure 28 we present the short-term output effects of the supply shock in country 1 assuming the regime of monetary independence where each country maintains its own central bank and sets its own desired interest rate. The contrast with the regime of monetary union is a strong one. We now find that the negative output effects of country 1's supply shock are significantly smaller in country 2 than in country 1 . In addition, the negative output effects in country 1 are now much larger than in the case of a monetary union. This has everything to do with the fact that each central bank sets its own interest rate. Thus, country 
1's central bank sets a higher interest rate than in the monetary union case because it only takes into account the inflation of country 1 (that has increased a lot because of the supply shock). In country 2 we have the reverse. That country's central bank in fact lowers the interest rate because output is negatively affected by country's supply shock (while inflation is little affected). As a result, the real interest rate in country 2 declines thereby offsetting the negative output transmission from country 1.

We obtain a similar relation between short-term output effects and animal spirits in country 2 as in the previous section (see Figure 29).

Figure 28: Short-term output responses to supply shock in country 1

\section{Country 1}

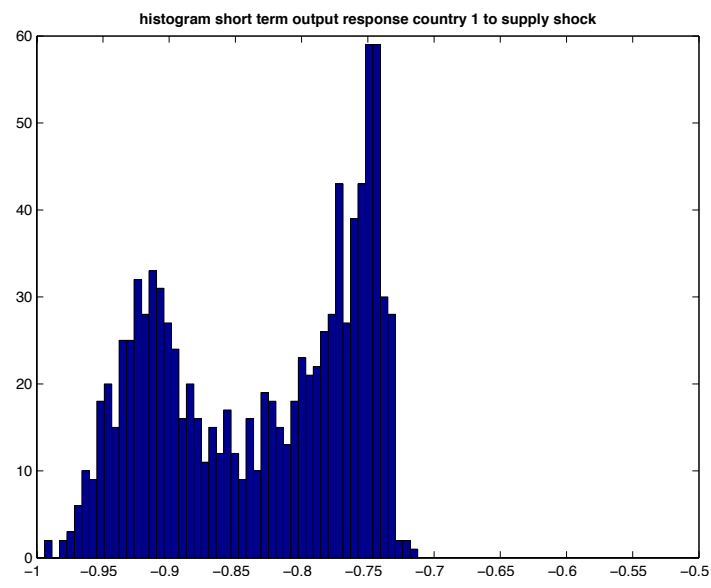

Country 2

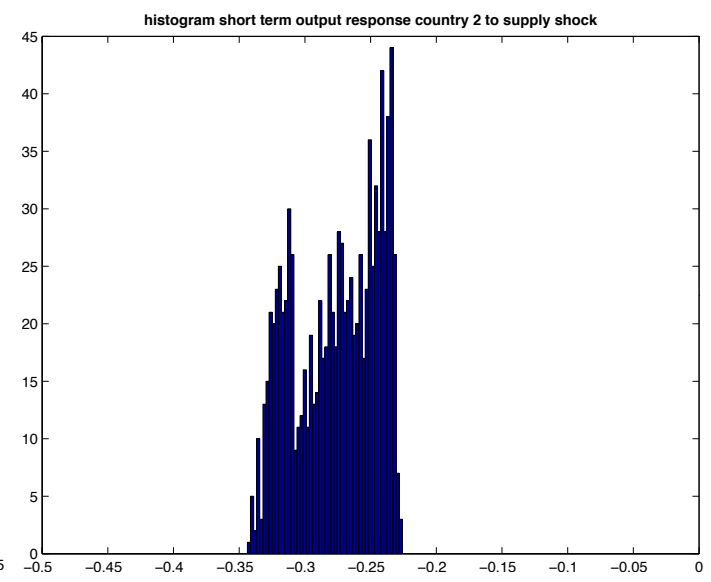

Figure 29: short-term output effects and animal spirits in country 2

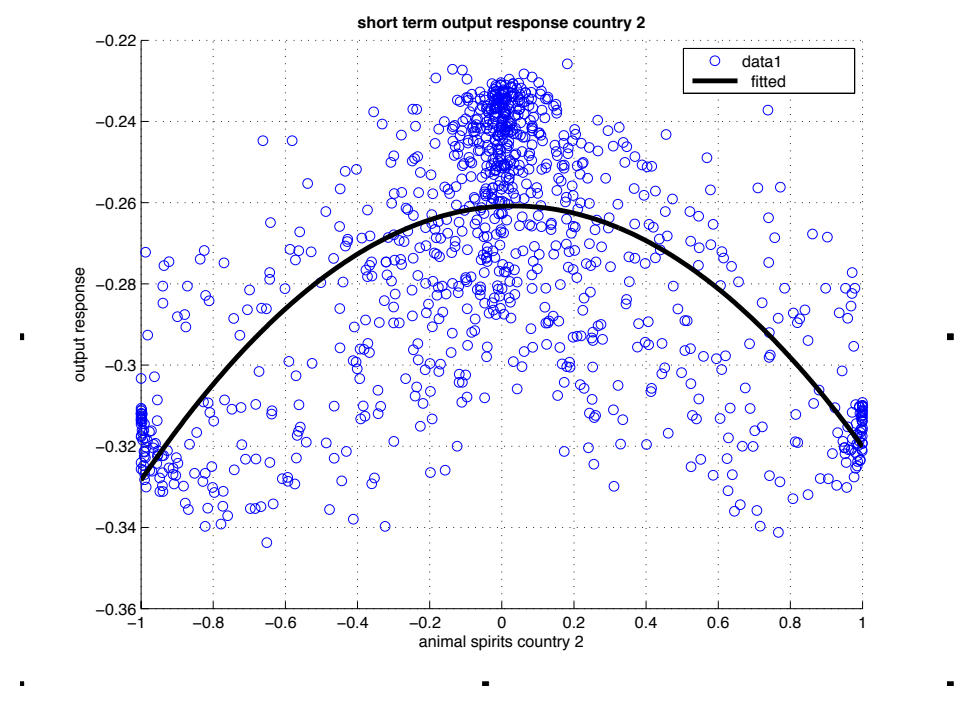




\section{Some empirical verification}

Animal spirits play an important role in our model and are at the core of the international transmission of business cycles. We have noted that the latter are highly correlated among industrialized countries. Can we observe a similar degree of correlation of animal spirits as our theoretical model predicts? In order to answer this question we have to find an empirical counterpart of animal spirits. We decided to select business sentiment indicators. These are collected in most countries. The OECD publishes such indicators for most member countries. We used these and computed the bilateral correlation coefficients during the sample period 1995-2014. We show these bilateral correlation coefficients for the Eurozone and the non-Eurozone OECD-countries in table 3.

We find quite large bilateral correlation coefficients that are of the same order of magnitude as those found for the business cycle components of the growth rates of output (see tables 1 and 2). We also observe that the bilateral correlation coefficients in the Eurozone are on average higher than among the other OECD countries, a result that our model also predicts.

Clearly, this empirical analysis can only be called partial. More empirical research is necessary. This is what we intend to do. 
Table 3: Bilateral correlations of business confidence index

Eurozone countries Correlation of business confidence index

\begin{tabular}{|c|c|c|c|c|c|c|c|}
\hline & austria & belgium & finland & france & germany & greece & ireland \\
\hline austria & 1.0000 & & & & & & \\
\hline belgium & 0.8551 & 1.0000 & & & & & \\
\hline finland & 0.8055 & 0.8901 & 1.0000 & & & & \\
\hline france & 0.7211 & 0.8295 & 0.8255 & 1.0000 & & & \\
\hline germany & 0.8979 & 0.8532 & 0.7610 & 0.7388 & 1.0000 & & \\
\hline greece & 0.3179 & 0.4565 & 0.5435 & 0.6260 & 0.2159 & 1.0000 & \\
\hline ireland & 0.3148 & 0.6257 & 0.6031 & 0.6454 & 0.5644 & 0.5207 & 1.0000 \\
\hline italy & 0.6379 & 0.7740 & 0.8243 & 0.8786 & 0.6635 & 0.7223 & 0.6767 \\
\hline netherlands & 0.7134 & 0.8397 & 0.8436 & 0.8576 & 0.7803 & 0.6865 & 0.7711 \\
\hline portugal & 0.5196 & 0.7159 & 0.7551 & 0.8279 & 0.5506 & 0.8056 & 0.6526 \\
\hline \multirow[t]{2}{*}{ spain } & 0.6172 & 0.7053 & 0.7932 & 0.8529 & 0.5413 & 0.8291 & 0.4719 \\
\hline & italy & nether s & portugal & spain & & & \\
\hline italy & 1.0000 & & & & & & \\
\hline netherlands & 0.8581 & 1.0000 & & & & & \\
\hline portugal & 0.8128 & 0.8821 & 1.0000 & & & & \\
\hline spain & 0.8552 & 0.8022 & 0.8507 & 1.0000 & & & \\
\hline
\end{tabular}

Stand-alone countries correlation of Business Confidence Index

\begin{tabular}{r|rrrrrrr} 
& austra a & czech & denmark & hungary & japan & korea & norway \\
\hline australia & 1.0000 & & & & & & \\
czech & 0.2203 & 1.0000 & & & & & \\
denmark & 0.1573 & 0.7358 & 1.0000 & & & & \\
hungary & 0.2829 & 0.6538 & 0.7191 & 1.0000 & & & \\
japan & 0.1322 & 0.7100 & 0.6118 & 0.4641 & 1.0000 & & \\
korea & -0.1042 & 0.0319 & 0.2308 & 0.4834 & -0.2284 & 1.0000 & \\
norway & 0.3020 & 0.7140 & 0.8034 & 0.6670 & 0.7021 & 0.2786 & 1.0000 \\
poland & 0.1350 & 0.7073 & 0.6189 & 0.6086 & 0.7228 & 0.1642 & 0.6680 \\
sweden & 0.2898 & 0.6951 & 0.7166 & 0.7535 & 0.4932 & 0.2392 & 0.6114 \\
switzerland & 0.1264 & 0.7504 & 0.6877 & 0.5777 & 0.6214 & 0.0400 & 0.6219 \\
uk & 0.2556 & 0.6779 & 0.7263 & 0.8065 & 0.6957 & 0.0582 & 0.6545 \\
us & 0.6672 & 0.3935 & 0.4621 & 0.4681 & 0.4211 & -0.0640 & 0.5495
\end{tabular}

\begin{tabular}{r|rrrrr} 
& poland & sweden switze d & uk & us \\
\hline poland & 1.0000 & & & & \\
sweden & 0.6962 & 1.0000 & & & \\
switzerland & 0.6972 & 0.7647 & 1.0000 & & \\
uk & 0.6452 & 0.6764 & 0.5609 & 1.0000 & \\
us & 0.3535 & 0.5281 & 0.2746 & 0.5276 & 1.0000
\end{tabular}




\section{Conclusion}

We started this paper by the observation that the degree of synchronization of the business cycles in the industrialized world is very high. It is also higher than what can be explained by trade flows. Mainstream macroeconomic models (Reals Business Cycle and DSGE) have found it difficult to replicate the high degree of synchronization in open economy versions of these models. In general they have only be able to do this by assuming sufficiently high correlations of exogenous shocks. Recent attempts to introduce financial flows in these models have been more successful but have also have to rely on assumptions that exogenous financial shocks are correlated, thereby admitting that much of the synchronization of the business cycles finds its origin outside the macroeconomic model.

In this paper we used a two-country behavioral macroeconomic model where the synchronization of the business cycle is produced endogenously. The main channel of synchronization occurs through a propagation of "animal spirits", i.e. waves of optimism and pessimism that get correlated internationally. We found that this propagation occurs with relatively low levels of trade integration. In addition, once a particular level of trade integration is reached further integration does not increase the synchronization of business cycles anymore.

We also found that the propagation of animal spirits and thus the synchronization of the business cycles is stronger among countries that are members of a monetary union than among "standalone countries" that have their own independent central banks. This difference occurs because in a monetary union the common central bank is a source of common shocks. This helps to introduce correlation between the animal spirits of the member countries.

The degree of output synchronization is very much influenced by the intensity with which the central bank stabilizes output. When that intensity is high, the central bank is able "to tame the animal spirits". In so doing it reduces the propagation dynamics of these animal spirits.

We also studied the transmission of a demand shock in one country towards the other country. We find that the size of the transmission very much depends on 
"initial conditions", i.e. the business cycle situation of the countries involved. When the business cycle is extreme, i.e. dominated by either extreme pessimism or optimism the transmission of the demand shock is significantly higher than when "Great Moderation" prevails. There is, however, great uncertainty about the size of this transmission. This uncertainty has to do with the initial conditions (the timing) of the shock.

Finally, we studied the transmission of a supply shock from one country to the other. We found that when countries are part of a monetary union, a negative supply shock in one country is transformed into a strong negative demand shock in the other country. This has to do with the fact that the common central bank reacts to the increased inflation produced by the supply shock by raising the union interest rate. As a result, the second country experiences an increase in the real interest rate and a decline in aggregate demand. This effect disappears in a regime where the countries are not members of a monetary union and set their own interest rates.

There are a number of limitations of our analysis. One is that the exchange rate channel in the transmission process was not modeled. This is of no importance for the monetary union model. It matters for the model of two standalone countries with their own central banks. We plan to research this channel in the future. 


\section{References}

Akerlof, G., and Shiller, R., (2009), Animal Spirits. How Human Psychology Drives the Economy and Why It Matters for Global Capitalism, Princeton University Press, 230pp.

Alpanda, S., and Aysun, U., (2014), International Transmission of financial shocks in an estimated DSGE model, Journal of International Money and Finance, 47, 21-55.

Anagnostopoulos, A., Licandro, O., Bove, I., Schlag, K., (2007), An evolutionary theory of inflation inertia, Journal of the European Economic Association, 5, 433-443.

Anderson, S., de Palma, A., Thisse, J.-F., 1992, Discrete Choice Theory of Product Differentiation, MIT Press, Cambridge, Mass.

Artis, M., and Cleays, P., (2005), What holds cycles together?, European University Institute, Discussion Paper.

Backus, D, Kehoe, P., and Kydland, F., (1992), International Real Business Cycles, Journal of Political Economy, vol 100, no 4, 745-775.

Blattner, T., and Margaritov, (2010), Towards a Robust Policy Rule for the Euro Area, ECB Working Paper Series, no. 1210, June

Bordo and Helbling(2004)).

Branch, W., and Evans, G., (2006), Intrinsic heterogeneity in expectation formation, Journal of Economic theory, 127, 264-95.

Brock, W., and Hommes, C., (1997), A Rational Route to Randomness, Econometrica, 65, 1059-1095

Calvo, G., (1983), Staggered prices in a utility maximizing framework. Journal of Monetetary Econ.onomics12, 383-398.

Canova, F., and H. Dellas, (1993) "Trade interdependence and the international business cycle”, Journal of International Economics, 34, 23-47.

De Grauwe, P., (2012), Lectures on Behavioral Macroeconomics, Princeton University Press.

De Grauwe, Paul and Grimaldi, Marianna (2006) "The exchange rate in behavioral finance framework", Princeton University Press, Princeton, NJ, USA. ISBN 9780691121635

Devereux, M.B., Yetman, J., (2010), Leverage constraints and the international transmission of shocks. Journal of Money, Credit and Banking, 42, 71-105.

Farmer, Roger, E.A., (2006), Animal Spirits, Palgrave Dictionary of Economics.

Frankel, J.A. and A. Rose (1998) The Endogeneity of the Optimum Currency Area Criteria", Economic Journal, 108, July, 1009-1025.

Galí, J., (2008), Monetary Policy, Inflation and the Business Cycle, Princeton University Press, 203pp. 
Gertler, M., Gilchrist, S., Natalucci, F.M., (2007), External constraints on monetary policy and the financial accelerator. Journal of Money, Credit and Banking, 39, 295-330

Giannone, D., Lenza, M., and Reichlin, L., (2008), Business Cycles in the Euro Area, NBER Working Paper, no. 14529, Cambridge, Mass.

Gigerenzer, G., and P.M. Todd, (1999), Simple Heuristics That Make Us Smart. New York: Oxford University Press.

De Haan, J., Inklaar, R., \& Jong-A-Pin, R. (2008). Will business cycles in the euro area converge? A critical survey of empirical research. Journal of economic surveys, 22(2), 234-273.

Kahneman, D., 2002, Maps of Bounded Rationality: A Perspective on Intuitive Judgment and Choice, Nobel Prize Lecture, December 8, Stockholm (also published in American Economic Review, 2003).

Kollmann, R., (1995), Consumption, real exchange rates, and the structure of international asset markets. J. Int. Money Financ. 14, 191-211.

Kollmann, R., (2012), Global Banks, Financial Shocks and International Business Cycles: Evidence from an Estimated Model. Centre for Economic Policy Research. Discussion Paper No. 8985.

Kollmann, R., Enders, Z., Müller, G., (2011), Global banking and international business cycles. Eur. Econ. Rev. 55, 407e426.

Pfajfar, D. and Žakelj, B., (2009), Experimental evidence on inflation expectation formation. Tilburg University.

Rey, H., (2014), International Channels of Transmission of Monetary Policy and the Mundellian Trilemma, Mundell Fleming Lecture, International Monetary Fund, Washington D.C., November.

Woodford, M., (2003), Interest and Prices: Foundations of a Theory of Monetary Policy, Princeton University Press.

Yao, W., (2012), International Business Cycles and Financial Frictions. Bank of Canada. Working Paper No. 2012-19.

Zimmermann, C., (1997), International real business cycles among heterogeneous countries. European Econonomic Review, 41, 319-356 


\section{Appendix 1: Solving the model}

\section{(1) Common central bank}

The solution of the model is found by first substituting (1.7) into (1.3) and (1.4) and rewriting in matrix notation. This yields:

$$
\begin{aligned}
& {\left[\begin{array}{cccc}
1-0.5 * a 2 * c 2 & -a 3-0.5 * a 2 * c 2 & -0.5 * a 2 * c 1 & -0.5 * a 2 * c 1 \\
-a 3-0.5 * a 2 * c 2 & 1-0.5 * a 2 * c 2 & -0.5 * a 2 * c 1 & -0.5 * a 2 * c 1 \\
-b 2 & 0 & 1 & 0
\end{array}\right]\left[\begin{array}{c}
y_{t}^{1} \\
y_{t}^{2} \\
\pi_{t}^{1} \\
\pi_{t}^{2}
\end{array}\right]=} \\
& {\left[\begin{array}{cccc}
a 1 /(1+m) & 0 & -a 2 & 0 \\
0 & a 1 /(1+m) & 0 & -a 2 \\
0 & 0 & b 1 & 0 \\
0 & 0 & 0 & b 1
\end{array}\right]\left[\begin{array}{c}
\tilde{E}_{t} y_{t}^{1} \\
\tilde{E}_{t} y_{t}^{2} \\
\tilde{E}_{t} \pi_{t}^{1} \\
\tilde{E}_{t} \pi_{t}^{2}
\end{array}\right]+} \\
& {\left[\begin{array}{cccc}
1-a 1 /(1+m) & 0 & 0 & 0 \\
0 & 1-a 1 /(1+m) & 0 & 0 \\
0 & 0 & 1-b 1 & 0 \\
0 & 0 & 0 & 1-b 1
\end{array}\right]\left[\begin{array}{c}
y_{t-1}^{1} \\
y_{t-1}^{2} \\
\pi_{t-1}^{1} \\
\pi_{t-1}^{2}
\end{array}\right]+\left[\begin{array}{c}
a 2 * c 3 \\
a 2 * c 3 \\
0 \\
0
\end{array}\right] r_{t-1}+\left[\begin{array}{c}
a 2 * u_{t}+\varepsilon_{t}^{1} \\
a 2 * u_{t}+\varepsilon_{t}^{2} \\
\eta_{t}^{1} \\
\eta_{t}^{2}
\end{array}\right]}
\end{aligned}
$$

Or

$$
A Z_{t}=B \widetilde{E_{t}} Z_{t+1}+C Z_{t-1}+b r_{t-1}+v_{t}
$$

where bold characters refer to matrices and vectors. The solution for $\boldsymbol{Z}_{t}$ is given by

$$
Z_{t}=A^{-1}\left[B \widetilde{E_{t}} Z_{t+1}+C Z_{t-1}+b r_{t-1}+v_{t}\right]
$$

The solution exists if the matrix $\boldsymbol{A}$ is non-singular. The system (A2) describes the solution for $y_{t}$ and $\pi_{t}$ given the forecasts of $y_{t}$ and $\pi_{t}$. The latter have been specified in equations (2.1) to (2.9) and can be substituted into (A2). Finally, the solution for $r_{t}$ is found by substituting $y_{t}$ and $\pi_{t}$ obtained from (A2) into (1.7).

The model has non-linear features making it difficult to arrive at analytical solutions. That is why we will use numerical methods to analyze its dynamics. In order to do so, we have to calibrate the model, i.e. to select numerical values for the parameters of the model. In appendix 2 the parameters used in the calibration exercise are presented. They are based on Gali(2007). The model was calibrated in such a way that the time units can be considered to be quarters. A sensitivity analysis of the main results to changes in the some of the parameters 
of the model will be presented. The three shocks (demand shocks, supply shocks and interest rate shocks) are independently and identically distributed (i.i.d.) with standard deviations of $0.5 \%$. We allow the demand and supply shocks to be correlated across countries. It will turn out that these correlations affect the transmission of business cycles across countries.

\section{(2) Two country model with 2 central banks}

Similar to the solutions to the model of a common central bank, we have the following for a two country model with 2 central banks.

$$
\begin{aligned}
& {\left[\begin{array}{cccc}
1-a 2 * c 2 & -a 3 & -a 2 * c 1 & 0 \\
-a 3 & 1-a 2 * c 2 & 0 & -a 2 * c 1 \\
-b 2 & 0 & 1 & 0 \\
0 & -b 2 & 0 & 1
\end{array}\right]\left[\begin{array}{c}
y_{t}^{1} \\
y_{t}^{2} \\
\pi_{t}^{1} \\
\pi_{t}^{2}
\end{array}\right]} \\
& =\left[\begin{array}{cccc}
a 1 /(1+m) & 0 & -a 2 & 0 \\
0 & a 1 /(1+m) & 0 & -a 2 \\
0 & 0 & b 1 & 0 \\
0 & 0 & 0 & b 1
\end{array}\right]\left[\begin{array}{c}
\widetilde{E}_{t} y_{t}^{1} \\
\widetilde{E}_{t} y_{t}^{2} \\
\widetilde{E}_{t} \pi_{t}^{1} \\
\widetilde{E}_{t} \pi_{t}^{2}
\end{array}\right] \\
& +\left[\begin{array}{cccc}
(1-a 1) /(1+m) & 0 & 0 & 0 \\
0 & (1-a 1) /(1+m) & 0 & 0 \\
0 & 0 & 1-b 1 & 0 \\
0 & 0 & 0 & 1-b 1
\end{array}\right]\left[\begin{array}{c}
y_{t-1}^{1} \\
y_{t-1}^{2} \\
\pi_{t-1}^{1} \\
\pi_{t-1}^{2}
\end{array}\right]+\left[\begin{array}{c}
a 2 * c 3 \\
0 \\
0 \\
0
\end{array}\right] r_{t-1}^{1} \\
& +\left[\begin{array}{c}
0 \\
a 2 * c 3 \\
0 \\
0
\end{array}\right] r_{t-1}^{2}+\left[\begin{array}{c}
a 2 * u_{t}+\varepsilon_{t}^{1} \\
a 2 * u_{t}+\varepsilon_{t}^{2} \\
\eta_{t}^{1} \\
\eta_{t}^{2}
\end{array}\right]
\end{aligned}
$$

Or

$$
A Z_{t}=B \widetilde{E_{t}} Z_{t+1}+C Z_{t-1}+b 1 r_{t-1}^{1}+b 2 r_{t-1}^{2}+v_{t}
$$

where bold characters refer to matrices and vectors. The solution for $\boldsymbol{Z}_{\boldsymbol{t}}$ is given by

$$
Z_{t}=A^{-1}\left[B \widetilde{E_{t}} Z_{t+1}+C Z_{t-1}+b 1 r_{t-1}^{1}+b 2 r_{t-1}^{2}+v_{t}\right]
$$




\section{Appendix 2: Standard parameter values of the calibrated model}

$\mathrm{p}^{*}=0$;

$\mathrm{a} 1=0.5$;

$\mathrm{a} 2=-0.2 ;$

$\mathrm{b} 1=0.5$;

b2 $=0.05$;

$\mathrm{c} 1=1.5$;

$\mathrm{c} 2=0.5$

c3 $=0.8$;

$\beta=1$;

$\delta=2$;

gamma $=1$;

sigma1 $=0.2$;

sigma2 $=0.2$;

sigma3 $=0.2$;

sigma $4=0.5$;

rho=0.5;

$\mathrm{m}=0.3$

zett $=0.2$
$\%$ the central bank's inflation target

$\%$ coefficient of expected output in output equation

$\%$ a is the interest elasticity of output demand

$\% \mathrm{~b} 1$ is coefficient of expected inflation in inflation equation

$\% \mathrm{~b} 2$ is coefficient of output in inflation equation

$\% \mathrm{c} 1$ is coefficient of inflation in Taylor equation

$\% c 2$ is coefficient of output in Taylor equation

\%interest smoothing parameter in Taylor equation

$\%$ fixed divergence in beliefs

$\%$ variable component in divergence of beliefs

$\%$ intensity of choice parameter

\%standard deviation shocks output

\%standard deviation shocks inflation

\%standard deviation shocks Taylor

$\%$ shock in impulse responses

\%rho measures the speed of declining weights in mean squares errors (memory parameter)

$\%$ propensity to import

$\%$ correlation of common shock 